\title{
Assessing Intrusion by the Capillary During Spatially Resolved Mass Spectrometry Measurement
}

\author{
Hoang Nguyen, Po Yu Peng, Dan Luss*, and Michael P. Harold* \\ Department of Chemical \& Biomolecular Engineering, University of Houston, \\ Houston, TX 77204-4004, United States \\ ("Corresponding authors: mharold@uh.edu, dluss@uh.edu)
}

\begin{abstract}
The impact of the capillary probe of a spatially-resolved mass spectrometer system (SpaciMS) on the measured reactant conversion is reported using propylene oxidation over $\mathrm{Pt} / \mathrm{Al}_{2} \mathrm{O}_{3}$ washcoated monoliths. The findings suggest that the invasive nature of SpaciMS depends on its configuration and application. Using monoliths with a range of cell densities (100 to 600 cells per square inch, CPSI), the concentration profiles of propylene sampled with probes of two different outer diameters $(170$ and $363 \mu \mathrm{m})$ are compared with the temperature measured using coherent optical frequency domain reflectometry (c-OFDR). The comparison indicates that flow blockage has a negligible effect if the limiting propylene is depleted in the downstream reactor section. Suction by the probe compensates for the blockage for certain combinations of the channel diameter and probe size. In such cases the profile measured by a probe with the larger outer diameter $(363 \mu \mathrm{m})$ is similar to that measured by a smaller capillary $(170 \mu \mathrm{m})$. The experiments reveal that the axial position of the probe does not influence the flow profile in a 100 CPSI monolith channel, nor does it affect the amount of flow deflected to surrounding channels for a 600 CPSI monolith. Under some conditions the results are impacted by transverse concentration gradients. Their existence complicates the interpretation of the SpaciMS data. The difference between the location of propylene depletion and temperature maximum provides a useful metric for capturing the collective impacts of flow deflection and transverse gradients. The complexity of the flow, transport and reaction suggests that at least three dimensionless groups are needed to bound the operating regions in which the presence of the probe has minimal impact on the measured concentration.
\end{abstract}

Keywords: propylene; oxidation; monolith; mass spectrometry; SpaciMS, c-OFDR 


\section{Introduction}

Experiments resolving in-situ spatial distributions of concentration and temperature provide a deeper understanding of complex catalytic reaction systems [1]. The spatially-resolved capillary inlet mass spectrometry, commonly referred to as SpaciMS, developed by Partridge and coworkers at Oak Ridge National Laboratory (ORNL) [2], enables in situ measurement of reacting species concentration inside catalytic reactors. This method involves the insertion of a fused-silica capillary tube into a continuous void in the reactor, such as a drilled hole in ceramic foam or the channel of a monolith. The local reactive gas is sucked by the capillary toward a mass spectrometer for sampling. This technique has been instrumental in clarifying certain mechanistic features in various reactor systems: e.g., Partridge's group studied the effect of sulfur on $\mathrm{NO}_{\mathrm{x}}$ reduction catalyst and found that the sulfation increased the ammonia production rate due to the shrinkage of the downstream oxygen storage zone [3]. Soran et al. used a SpaciMS to validate the global kinetic model that predicts the formation and utilization of ammonia in the $\mathrm{NO}_{\mathrm{x}}$ storage and reduction catalyst [4]. Li et al. [5] used SpaciMS to resolve species concentrations in a sequential Lean $\mathrm{NO}_{\mathrm{x}}$ Trap and Selective Catalytic Reduction (LNT + SCR) reactor system, while Bugosh et al. [6] the same technique to study the anomalous steady state for methane oxidation on $\mathrm{Pt} / \mathrm{Pd} / \mathrm{Al}_{2} \mathrm{O}_{3}$ monolith reactor. These and other insightful studies demonstrated the usefulness of the SpaciMS technique.

The SpaciMS probe may affect the flow in a monolith channel, the void of a foam, etc. and therefore alter the axial concentration profile. This potential intrusion has led to an ongoing debate on the accuracy of the method. Resolution of the debate is exacerbated by differences in SpaciMS configurations and implementations as well as experimental methods. Complicating factors include the extent of flow blockage and variations in the suction rate by capillary probe, 
boundary layer transport limitations, among other factors. Sa et al [7] used computational fluid dynamics (CFD) to simulate the influence of the probe during $\mathrm{CO}$ oxidation. Assuming that the inlet velocity is the same for all monolith channels, they concluded that the probe's influence was negligible. On the other hand, Hettel et al. [8] argued that the assumption of equal flow distribution in all the monolith channels may not be valid. Using CFD simulations of the catalytic partial oxidation of methane, they showed that the blockage caused the conversion in a channel containing the probe to exceed that in a channel without a probe. The simulations reveal that the blockage impact is significant even when the probe occupied only $3.5 \%$ the channel area. Goguet and Partridge et al. [9] argued that the SpaciMS method provides an accurate measurement of the concentration with negligible intrusion. Morgan et al. also conducted several experiments to check the invasiveness nature of the capillary probe [1]. The extent of blockage depends on the position of the probe within the channel cross-section, with the largest impact when the probe is at the channel center [8]. For reactors that are positioned horizontally the probe tends to lie on the bottom wall of the channel due to gravity while for vertical reactors the flexible nature of the probe casts doubt on its location. Thus flow blockage by the probe is difficult to predict without knowing its position.

In the current study, to gain a deeper understanding with the goal of providing some guidance, we conducted experiments using SpaciMS comprising two different capillary probe sizes to measure the intra-channel concentration profile during the complete oxidation of propylene on $\mathrm{Pt} / \mathrm{Al}_{2} \mathrm{O}_{3}$ washcoated monoliths of several different CPSIs. The experiments were targeted to assess the impact of the capillary probe in different combinations of monolith crosssection sizes and capillary diameters. Spatial intra-channel fluid temperature profiles were measured using the coherent Optical Domain Reflectometry (c-OFDR), a technique described 
elsewhere [10]. In the absence of a probe, a linear relation exists between the limiting reactant conversion in one channel and the temperature in the adjacent channel. A position difference between the propylene depletion point and the local temperature maximum would suggest that the concentration measurement is affected by the probe. Additional experiments are conducted to assess the impact of transverse concentration gradients. To this end, the findings of this study provide useful guidance on the veracity of SpaciMS as an in situ reactor diagnostic tool for various configurations and applications. The invasiveness extent may be assessed to determine the costs and benefits of a particular design change. For example, an increase in the capillary size and sampling rate may benefit the temporal resolution at the expense of flow blockage. This can guide experimentalists to make the best design decisions for a particular application.

\section{Experimental Setup and Procedure}

The complete oxidation of 0.17 vol. $\%$ propylene and 10 vol. $\% \mathrm{O}_{2}$ was conducted in a $7.5 \mathrm{~cm}$ long, $2.54 \mathrm{~cm}$ diameter catalytic cordierite monolith catalyst with channel densities of 100, 200, 400 and 600. Blank monoliths (100, 200, and 600 CPSIs) were provided by Corning Inc. (Corning, NY). A Pt/ $\mathrm{Al}_{2} \mathrm{O}_{3}$ catalytic washcoat was deposited on these monoliths via a dip coating method described in [11] to achieve a washcoat loading of $2.3 \mathrm{~g} / \mathrm{in}^{3}$ and a Pt loading of $23.8 \mathrm{~g} / \mathrm{ft}^{3}$. A commercial $400 \mathrm{CPSI}$ monolith was provided by BASF (Iselin, NJ). This monolith has $2.3 \mathrm{~g} / \mathrm{in}^{3}$ washcoat loading and $96 \mathrm{~g} / \mathrm{ft}^{3} \mathrm{Pt}$ loading. Table 1 summarizes the structural characteristics of the different CPSI monolith reactors.

Table 1.

The experimental setup using both a SpaciMS and c-OFDR is described elsewhere [12]. Figure 1 shows a schematic and a picture of the sampling system in the vicinity of the upstream of the monolith. The temperature profile was measured by a stationary $125 \mu \mathrm{m}$ outer diameter 
optical fiber placed in the center channel of the monolith. Temperature measurement by the cOFDR has several advantages compared to that by thermocouples; i.e., it is not subject to heat conduction along the fiber's body. The small fiber size, fast sampling rate, and distributed temperature measurement capability enables its use in both transient and steady state studies. The fiber provides a continuous spatial temperature profile with $\pm 1^{\circ} \mathrm{C}$ accuracy. It is essential to accurately identify the entrance location of the monolith to enable accurate comparison of the spatial temperature and concentration profiles. Thus, a portion of the fiber near the entrance was coated with Aquadag $^{\mathrm{TM}}$ that increases its laser absorbance. A $200 \mathrm{~mW}$ GX3 green laser pointer (beam diameter $\sim 2 \mathrm{~mm}$ ) directed to this position created a local hotspot, which was detected on the measured temperature profile. Using this technique, the axial position of the measured temperature profile is off by at most $\pm 2 \mathrm{~mm}$. The feed entrance temperature was also monitored by a K-type Omega stainless steel sheathed thermocouple $(\mathrm{OD}=0.5 \mathrm{~mm})$, positioned $0.5 \mathrm{~cm}$ upstream of the monolith front face. That signal was used to monitor the feed temperature and calibrate the optical fiber before the start of each experiment.

Figure 1.

Two fused silica SGE capillary tubes (OD $=363 \mu \mathrm{m}, \mathrm{ID}=150 \mu \mathrm{m} \& \mathrm{OD}=170 \mu \mathrm{m}$ and $\mathrm{ID}=110 \mu \mathrm{m})$ were used to measure the concentrations. The suction rates of the capillary tubes depend on the capillary internal diameter and other factors. These are estimated and provided later in the paper. The capillary was inserted into a septum in the downstream section of the reactor channel. The other end was mounted on a linear translation stage and connected to the mass spectrometer through a micro Valco ${ }^{\circledR}$ fitting. The gas flowed under suction into the probe and through the fiber to a quadruple mass spectrometer (QMS-Omnistar GSD 300). The position error associated with the spatial concentration profile was about $\pm 2 \mathrm{~mm}$. 
The reactor reached a steady state profile after two hours. A typical concentration profile was established as follows. The capillary probe was moved from the upstream to the downstream end to construct a complete concentration profile. At each axial sampling point, the propylene concentration was measured for $\sim 10$ minutes, allowing the value to reach a time-invariant level. The spatial concentration was reported by averaging the values over a period of at most two minutes. The reported dimensionless concentration is the ratio between the measured to inlet concentration. The use of dimensionless concentration improved the accuracy of identifying the depletion location of propylene gas. To ensure that channel concentration profiles were representative of the overall monolith, the experiment was conducted in different channels, which were randomly chosen among eight channels surrounding the reference channel, to confirm an observed trend. This minimized the likelihood of atypical data due to non-uniformity in washcoat thickness between the channels that can produce regions of different catalytic activity.

Unless otherwise stated, the propylene oxidation was conducted under steady state conditions with a feed comprising 0.17 vol. $\% \mathrm{C}_{3} \mathrm{H}_{6}, 10$ vol. $\% \mathrm{O}_{2}$ and the balance Argon. Both the total flow rate and feed temperature were between 8000 to $11000 \mathrm{sccm}$ and 50 to $250{ }^{\circ} \mathrm{C}$, respectively. The adiabatic temperature rise for this feed composition is estimated to be $158{ }^{\circ} \mathrm{C}$. The gas hourly space velocity (GHSV) range corresponding to this range of flow rates is 12640 to $17380 \mathrm{~h}^{-1}$ (standard conditions). The feed temperature was varied by adjustment of the furnace temperature. 


\section{Experimental Results and Discussion}

\section{Impact of the probe axial position}

A set of experiments examined the impact of the axial position of the capillary probe by measuring the temperature profile using the c-OFDR at a given position of the probe. For a 100 CPSI monolith, the measurements were accomplished with the $125 \mu \mathrm{m}$ c-OFDR fiber and 363 $\mu \mathrm{m}$ SpaciMS probe in the same channel. (Below we discuss the 600 CPSI results shown in Fig. 2.b.) The fiber and probe occupy $0.2 \%$ and $1.6 \%$ of the channel cross sectional area, respectively. The feed flow rate and temperature in this experiment were $8000 \mathrm{sccm}$ and $200^{\circ} \mathrm{C}$, respectively. While the fiber was stationary, the probe was moved along the channel and sampled at about 20 distinct points. The temperature profile was measured while the probe was at either one of these positions indicated in Fig. 2a as upstream (position A), midstream (position B), and downstream (position C). Obviously, the probe occupied a different length or volume fraction of the channel at each axial position. The experiment was conducted to check if the flow rate into the channel and blockage varies with the probe position. In turn, this could affect the gas residence time or alter the measured concentration profile. Specifically, the blockage is expected to be more significant with the probe in position $\mathrm{A}$ than that in position $\mathrm{C}$, resulting in a lower flow rate for $\mathrm{A}$ than $\mathrm{C}$. This change could be detected by the measured temperature profile. Given the finite thermal conductivity of the fused silica capillary of $1.38 \mathrm{~W} /(\mathrm{m} \mathrm{K})$ a question raised earlier by Horn et al. [13] is whether heat conduction along the probe may further impact the results. We detected no change in the temperature profile in these steady state experiments. Similar findings were obtained at a higher flow rate of $11000 \mathrm{sccm}$ (not shown here).

It is noted that the measured temperature rise $\left(\sim 100{ }^{\circ} \mathrm{C}\right)$ is lower than the calculated value $\left(\sim 158^{\circ} \mathrm{C}\right)$ for the given feed concentration of propylene. This is attributed to a couple of factors. First, we cannot rule out heat losses which would suppress the asymptotic value of the 
temperature. Second, as we elaborate below, the c-OFDR fiber measures the fluid temperature which is necessarily different (lower) than the solid temperature. The latter would be anticipated to approach the expected value of the temperature rise in the absence of heat losses.

Figure 2.

A similar set of experiments were conducted to check if the probe position affected transient measurements. Fig. 3 shows the evolving temperature profiles when the feed propylene concentration was increased from 0 to $0.17 \%$ at $t=0 \mathrm{~s}$ for a feed temperature of $81^{\circ} \mathrm{C}$ (Fig. 3A) or at $101^{\circ} \mathrm{C}$ (Fig. 3B), respectively, with $363 \mu \mathrm{m}$ OD capillary tube in the commercial $400 \mathrm{CPSI}$ monolith catalyst. Two sets of experiments were conducted: one with the capillary probe fully occupied the channel and the other with the probe removed entirely from the monolith. As in the results in Fig. 2.a, the optical fiber and the capillary tube were contained in the same channel. Reasonably close agreement was obtained between the two temperature profiles when the reaction ignited and the thermal wave propagated upstream. These results indicated the capillary probe position has negligible impact even under transient experiments.

Figure 3.

The steady-state and transient results suggest that the probe axial position for this particular combination of monolith and probe is negligible as the measured temperature profiles were essentially identical when the probe was in different positions. The invariance of the measured temperature profile suggests that the axial position of the probe has a minimal impact on the extent of reaction for low density 100 CPSI monolith.

To examine the generality of these transient results, the same experiment was conducted in a monolith with the highest cell density (600 CPSI). Due to the much narrower channel size, it was not possible to insert both probes into the same channel without influencing the temperature 
reading. Hence, the optical fiber was inserted in the channel adjacent to the one housing the capillary probe. Fig. $2 \mathrm{~b}$ shows that, just as for the 100 CPSI monolith results, the temperature profile in the adjacent channel is not influenced by the position of the capillary tube in channel. This indicates that the axial position of the probe position has a negligible influence over the flow in adjacent channels. These results are consistent with the simulation findings of Hettel et al. [8] and Sa et al. [7] who showed the probe position has only a minor impact on the flow to neighboring channels without a probe. Our findings further suggest that the small amount of gas blocked by the probe is distributed among several adjacent empty channels. The net effect is that the probe positon does not cause a significant shift in the flow to the adjacent channels. Finally, it is noted that these experiments do not rule out an impact of the probe position on the measured concentration profile by the probe. This is examined in the next section.

\section{Impact of suction by capillary probe}

The gas suction by the capillary is typically a small fraction of the feed to the channel and is therefore ignored. As the suction may counteract the flow blockage by the probe, it is important to estimate and compare the magnitudes of these two effects. The flow by suction can be measured by several methods involving flow meter and transient residence time analysis, such as connecting a manometer to a SpaciMS capillary [13] or by estimating its magnitude with a model. Here we follow the latter approach.

Connecting a capillary probe to the SpaciMS generates a large pressure drop: the sampling point (capillary mouth) is exposed to atmospheric pressure $\left(\approx 10^{5} \mathrm{~Pa}\right)$, while the outlet is under high vacuum $\left(\approx 4 \cdot 10^{-6} \mathrm{~Pa}\right)$. At very low pressure, the mean free path of a gas molecule is comparable to the probe diameter and significant interaction occurs between individual gas molecules and the tube wall. Due to the violation of the no-slip boundary condition, the flow in 
the capillary may significantly deviate from the prediction by the classical Navier-Stokes equations. Several investigators attempted to account for the wall effect using the Maxwell slip velocities, but these approaches are often too complicated for the current application [14].

Dongari et.al [15] developed a simple prediction based on the classical Hagen-Poiseuille model of an incompressible laminar Newtonian fluid in a tube. They argued that under isothermal conditions the nonzero fluid velocity at the wall is determined by the boundary condition:

$$
\rho U=-\frac{\mu}{P}\left(\frac{d P}{d z}\right) \quad \text { at } \mathrm{r}=\mathrm{r}_{\mathrm{i}}
$$

where $U$ is the fluid velocity at the capillary tube wall $(\mathrm{m} / \mathrm{s}), \mathrm{r}_{\mathrm{i}}$ the inner radius of the capillary (m), and $\mu$ (Pa s) and $\rho\left(\mathrm{kg} / \mathrm{m}^{3}\right)$ are the fluid viscosity and density, respectively. Solving the Navier-Stoke equation with this boundary condition and applying the Bernoulli equation predicts the following suction mass flow rate:

$$
M_{s}=\frac{\pi \times r_{i}^{4}}{16 \mu L_{c a p} R_{m} T_{c a p}} \times\left[\frac{P_{a t m}}{1+\frac{F_{T}{ }^{2}}{2 R_{m} \times T \times N^{2} \times S^{4}}}\right]^{2}
$$

where $M_{s}$ is a mass suction flow rate $(\mathrm{kg} / \mathrm{s}), \mathrm{L}_{\text {cap }}$ the length of the capillary tube $(\mathrm{m}), \mathrm{T}_{\text {cap }}$ the isothermal temperature of the capillary tube, $R_{m}$ the mass-based gas constant $(J /(k g K)), F_{T}$ the total volumetric flow rate, $\mathrm{T}$ the temperature at the tip of the capillary tube, $\mathrm{N}$ the number of channels for the monolith reactor, $\mathrm{S}$ the side length of a channel, and $\mathrm{P}_{\text {in }}\left(\mathrm{P}_{\text {out }}\right)$ the inlet (outlet) pressure of the capillary (Pa). A detailed derivation is presented in Appendix B.

The blockage effect caused by geometrical impact of the capillary tube can be compensated for by the suction rate. The extent of that compensation depends on several factors, 
the important ones of which are contained in the modified Dongari formula, Eq. (2). The formula implies that an increasing internal capillary tube diameter increases the suction rate, but increasing the total flow rate decreases the suction, causing the blockage to be more significant. This prediction agrees with the Hettel et al. claim that the blockage impact increases at high space velocity [8].

We utilized Eq. (2) to estimate the ratio of the flow rate caused by suction into the probe and that blocked by the probe. This estimate helps interpret data shown below. The values of various model parameters are provided in Table 2.

Table 3 reports the estimates of the ratio between the flow rates caused by suction (using Eq. 2) and blocked by the probe. These were obtained for several different combinations of channel size (CPSI), probe size $\left(\mathrm{d}_{\mathrm{o}}, \mathrm{d}_{\mathrm{i}}\right)$, and a total feed rate of $8000 \mathrm{sccm}$. The predictions describe the impact of:

- Channel flow rate without a probe $\left(\mathrm{Q}_{\mathrm{ref}}\right)$,

$$
Q_{r e f}=\frac{F_{T}}{N}
$$

where $\mathrm{N}$ is the number of channels.

- The percentage of the channel cross section area occupied by the capillary probe

$$
\% \text { Occupied }=\frac{\pi \mathrm{d}_{\mathrm{o}}^{2}}{4 \times \mathrm{S}^{2}} \times 100 \%
$$

This expression assumes the blockage is caused only by the cross-sectional area $\left(\mathrm{S}^{2}\right)$ occupied by the probe.

- The blocked flow rate $\left(\mathrm{Q}_{\mathrm{b}}\right)$ is

$$
Q_{b}=Q_{r e f} \times(\% \text { Occupied }) / 100
$$


The amount of fluid being deflected by the capillary probe is due to the reduction of crosssectional area in a monolith channel, a boundary layer is formed at the probe's surface, among other factors. A numerical (CFD) analysis of the boundary effect caused by the probe is required as described by Hettel et al. [8] and Gossler et al. [16]. We assume the conservative estimate given by the cross-sectional area reduction caused by insertion of the probe. Thus ratio of the blockage to suction flow rates $\left(Q_{b} / Q_{s}\right)$ where $Q s=\rho_{s} M_{s}$ with $M_{s}$ given by Eqn. (2), likely is an underestimate. A ratio of order unity indicates that the suction compensates for the blocked flow; a ratio much smaller than unity indicates that suction over-compensates for the blocked flow; a ratio greatly exceeding unity indicates that the blocked flow is not influenced by suction.

\section{Table 2 .}

Table 3 .

With this in mind, we investigated the competing effects of blockage and suction during propylene oxidation in the 400 CPSI monolith reactor. The gas was sampled using two different probes $\left(\mathrm{d}_{\mathrm{o}}=170\right.$ and $\left.363 \mu \mathrm{m}\right)$ to assess the competition. The feed flow rate was $8000 \mathrm{sccm}$ and contained 0.17 vol. $\% \mathrm{C}_{3} \mathrm{H}_{6}, 10$ vol. $\% \mathrm{O}_{2}$, and balance Ar. The feed temperature was $180{ }^{\circ} \mathrm{C}$. Fig. 4a shows the surprising result that the concentration profiles measured by the two probes are essentially the same, i.e., the probe size did not affect the propylene conversion. A larger probe is expected to increase the blockage and hence alter the residence time in the channel, and consequently shifts the concentration profile upstream. That this did not occur suggests that the increased blockage was compensated by the suction. The suction flow rate prediction (Eqn. (2)) predicts that $\mathrm{M}_{\mathrm{s}} \propto r_{i}^{4}$ when the non-unity term in the denominator is negligible. For these 
conditions a larger internal diameter of the capillary probe increases the suction rate by a factor of $3.5(=150 / 110)^{4}$. The estimated ratio of the deflected and suction flow rates is of order unity (1.04 for the $170 \mu \mathrm{m}$ OD probe). Thus, any blocked flow is compensated for by the suction. This likely explains why the change in the probe size minimally affected the residence time and conversion in the channel. The results underscore the need to account for suction when assessing the net invasiveness extent.

Fig. $4 \mathrm{~b}$ shows that when the experiment was repeated at a higher flow rate $\left(\mathrm{F}_{\mathrm{T}}=11000\right.$ sccm) the concentration profile corresponding to the larger outer diameter probe $\left(\mathrm{d}_{\mathrm{o}}=363 \mu \mathrm{m}\right)$ was shifted by $1 \mathrm{~cm}$ upstream from the profile obtained with the smaller probe $\left(\mathrm{d}_{\mathrm{o}}=170 \mu \mathrm{m}\right)$. An increase in the total flow rate to the channel increases the magnitude of the $\mathrm{Q}_{\mathrm{b}} / \mathrm{Q}_{\mathrm{s}}$ ratio. At the higher flow rate the suction flow rate decreases (Eq. (2)). In turn the larger diameter probe increases $\mathrm{Q}_{\mathrm{b}}$. Thus blockage is not compensated by suction to the same degree as at $8000 \mathrm{sccm}$. The shift in the propylene concentration upstream reflects an increased conversion as a result of the increased residence time. This result is expected when suction is not important.

Figure 4.

We repeated the experiments reported in Fig. 4a in a 600 CPSI monolith with a feed temperature of $240^{\circ} \mathrm{C}$. Fig. $4 \mathrm{c}$ shows that the propylene concentration measured by the smaller outer diameter probe $(170 \mu \mathrm{m})$ is upstream of that using the larger probe $(363 \mu \mathrm{m})$. The large probe occupies about $6 \%$ (10\%) of the channel cross section in the 400 (600) CPSI monolith (Table 1). It is surprising that the conversion is lower for the larger probe, which has a longer residence time. We attribute this non-intuitive result to an external mass transfer limitation that generates a transverse concentration gradient within the channel at this higher feed temperature. 
That is, the smaller capillary probe samples gas that is closer to the surface than that by the larger probe. Hence, for the same center channel reactant concentration the smaller probe measures a lower concentration than the larger probe. It is noted that the results obtained for the $400 \mathrm{CPSI}$ monolith (Figs. 4A, 4B) are also impacted by transverse concentration gradients but perhaps not to the same degree at the lower temperature. There are competing effects. The flow blockage reduces the flow rate, leading to a larger residence time and conversion. On the other hand, the suction by the probe and the above-mentioned sampling effect in the presence of a transverse gradient effect tend to shift the concentration profile downstream; i.e. conversion decrease. Thus, any comparison of two different probe sizes requires consideration of these interacting effects. For the more porous monolith (400 CPSI) these interacting factors result in similar concentration profiles at the lower flowrate (Fig. 4A) while the blockage effect is more prominent at the higher flowrate (Fig. 4B). Finally, at higher temperature with the high density monolith (600 CPSI) the transverse gradient effect causes a qualitative shift in the impact of the probe size (Fig. 4C).

\section{Transverse concentration gradients}

An intra-channel concentration gradient transverse to flow can be detected as follows. We measured using the smaller probe the concentration at the end of the channel and about $3 \mathrm{~mm}$ from the channel outlet. This concentration is referred to as the cup mixing concentration, a term used to describe the concentration that results if the entire stream is collected in a cup, mixed, and the concentration measured. The concentration difference between the two points provides an estimate of the extent of transverse gradients. Our interpretation of these data assumes that the sampling concentration $3 \mathrm{~mm}$ beyond the channel exit enables sufficient mixing to distinguish the composition near the channel wall from that of 
the mixed effluent stream. Figs. 5a and 5b report the results for the 100 and 200 CPSI monoliths, respectively. Fig. 5a shows a significant difference in the propylene conversion at the end of the monolith (93\%) and the cup mixing value (54\%). The rather large conversion gap for the 100 CPSI monolith is attributed to an external mass transport resistance transverse to the axial flow in the 100 CPSI monolith, which has a wide channel and hence a longer diffusion distance. Fig. $5 \mathrm{~b}$ shows that the conversion gap decreased when the same propylene mixture was fed to the 200 CPSI monolith reactor at the same flow rate and at the lower feed temperature of $131^{\circ} \mathrm{C}$. In this case, the outlet conversion was about $95 \%$, while the cup mixing conversion was $80 \%$. Thus, the SpaciMS measurement enables an estimate of the transverse concentration gradient. This information is useful for data interpretation. It is noted that we measured (results not shown here) no concentration (conversion) difference between the end of channel and the effluent when the experiment was conducted at the much lower temperature the $\mathrm{T}_{\mathrm{f}}=65{ }^{\circ} \mathrm{C}$ for the $400 \mathrm{CPSI}$ monolith, and $\mathrm{T}_{\mathrm{f}}=150{ }^{\circ} \mathrm{C}$ for $600 \mathrm{CPSI}$ monolith. We attribute the higher transverse mass transfer rate in monoliths with a higher cell density to a decrease in the hydraulic diameter, and increase in the specific surface area of the substrate channels.

\section{Figure 5.}

A similar experimental approach was proposed by Morgan et. al. [1]. However, in that study the concentration difference was attributed the decreasing conversion beyond the exit point to invasiveness of the probe. In the current study, we attribute the trend to the difference between the cup mixing effluent concentration and the intra-channel concentration. That difference increases with an increase in the channel size of the monolith (CPSI increase).

We now revisit an earlier result in Fig. 4c which was attributed to a transverse concentration gradient. The relative size of the probe and the channel width (hydraulic radius) 
may impact the measured concentration: the probe samples a local concentration that is determined in part by its size relative to that of the channel and, as a result, may lead to misleading results under a steep concentration gradient. In contrast, if the probe is positioned in the center of channel, it is more likely to measure a higher reactant concentration than if located near the wall. A peripherally-nonuniform washcoat thickness may also cause differences between the gas sampled near the channel corner and at the midpoint along the wall. That said, peripheral variations are not likely to occur under strong external transport control since the surface concentration would be low around the channel periphery.

The extent and impact of the transverse transport in the capillary probe can be estimated by $\varphi$, defined as the ratio between the transverse diffusion time $\left(\tau_{\mathrm{d}}\right)$ and the reaction time $\left(\tau_{\mathrm{r}}\right)$ :

$$
\phi=\frac{\tau_{d}}{\tau_{r}}
$$

$\phi$ is a product of the transverse Peclet number $\left(\mathrm{Pe}_{\mathrm{t}}\right)$ and the Damkohler number (Da):

$$
\phi=\frac{\tau_{d}}{\tau_{c}} \times \frac{\tau_{c}}{\tau_{r}}=P e_{t} \times D a
$$

where $\tau_{\mathrm{c}}$ is the characteristic axial convection time. A small $\phi$ corresponds to kinetic control and a negligible concentration gradient, while a large $\varphi$ corresponds to transverse diffusion control and a steep concentration gradient.

The characteristic transverse transport time $\left(\tau_{d}\right)$ is an estimate of the diffusion time of the reactant propylene from the channel center to the wall. In the absence of a probe, $\tau_{\mathrm{d}}$ is the ratio of the square of the diffusion distance and the reactant gas phase bulk diffusivity $\left(\mathrm{D}_{\mathrm{f}}\right)$ :

$$
\tau_{d}=\frac{R_{\Omega_{1}}^{2}}{D_{f}}
$$


where the effective transverse length $R_{\Omega_{1}}$ is $\frac{A_{\Omega}}{P_{\Omega}}$, where $A_{\Omega}$ is the cross sectional channel area open to flow and $P_{\Omega}$ is the wetted perimeter. For a square channel $A_{\Omega}=\mathrm{S}^{2}$ and $P_{\Omega}=4 \mathrm{~S}$ where $\mathrm{S}$ is the effective length of a square channel, assuming a uniform washcoat thickness. In the presence of a probe, $R_{\Omega_{1}}=\frac{S^{2}-\frac{\pi d_{o}^{2}}{4}}{4 S+\pi d_{o}}$, where $\mathrm{d}_{\mathrm{o}}$ is the outer diameter of the capillary probe. Thus, the effective diffusion length and the diffusion time are shorter in the presence of the probe.

The reaction time $\left(\tau_{\mathrm{r}}\right)$ of propylene oxidation requires knowledge of the reaction kinetics. In excess oxygen, Pt-catalyzed propylene oxidation rate, $\mathrm{R}_{\mathrm{P}}$, is described by the LangmuirHinshelwood rate law

$$
r_{P}=\frac{k_{1} Y_{s}}{\left(1+k_{2} Y_{s}\right)^{2}}\left(\mathrm{~mol} / \mathrm{m}^{3} \text { washcoat/ } \mathrm{s}\right)
$$

where $\mathrm{Y}_{\mathrm{s}}$ is a circumferentially averaged mole fraction at the fluid-washcoat interface, and $\mathrm{k}_{1}$ and $\mathrm{k}_{2}$ are temperature-dependent kinetic parameters that satisfy the Arrhenius temperature dependence:

$$
k_{1}=b_{1} \times \exp \left(-\frac{b_{2}}{T_{s}}\right) \quad k_{2}=b_{3} \times \exp \left(-\frac{b_{4}}{T_{s}}\right)
$$

The rate predicts a maximum at an intermediate value of $\mathrm{Y}_{\mathrm{s}}$, consistent with previous experiments [17]. The limiting apparent propylene reaction order is unity for $k_{2} Y_{s} \rightarrow 0$ and -1 for $\mathrm{k}_{2} \mathrm{Y}_{\mathrm{s}} \gg$ 1. For example, under strong transverse diffusion limitations, $\mathrm{Y}_{\mathrm{s}}$ approaches 0 and the reaction order is unity. In general, $\tau_{\mathrm{r}}$ depends on the propylene concentration and therefore on the axial position. The characteristic reaction time is given by 


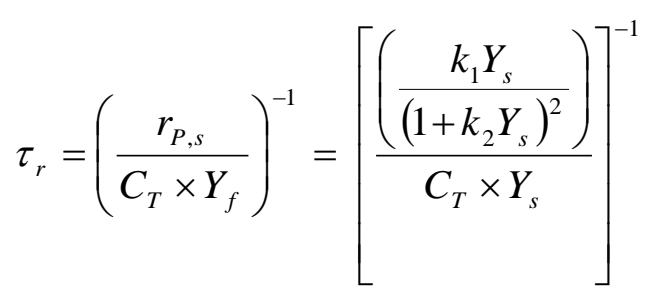

Where $\mathrm{C}_{\mathrm{T}}$ is the total molar concentration. One may estimate $\tau_{\mathrm{r}}$ at the point of depletion of propylene $(\mathrm{Ys} \rightarrow 0)$. Under these conditions the kinetics are linear and $\tau_{\mathrm{r}}$ simplifies to:

$$
\tau_{r}=\lim _{Y s \rightarrow 0}\left(\frac{r_{\mathrm{Pr}}}{C_{T} \times Y_{s}}\right)^{-1}=\frac{C_{T}}{k_{1}}
$$

Substitution of Eqns. (8) and (12) into Eqn. (6), gives

$$
\phi\left(Y_{s} \rightarrow 0\right)=\frac{R_{\Omega_{1}}^{2} \times k_{1}}{D_{f} \times C_{T}}
$$

Estimation of $k_{1}\left(b_{1}, b_{2}\right.$ in eqn. (10)) requires a fit of monolith reactor data under differential conditions. We describe the monolith model used for this estimation in Appendix A. The reactor model used is a 1-D low dimensional model following Joshi et al. [17], which has been successful in predicting a variety of different catalytic reaction systems, including $\mathrm{NO}_{\mathrm{x}}$ reduction by LNT catalysts [18], dynamic hysteresis of co-oxidation of $\mathrm{CO}$ and $\mathrm{C}_{3} \mathrm{H}_{6}$ [19], among others [20]. Diffusion and reaction in the washcoat is approximated by an internal mass transfer coefficient derived by averaging the washcoat differential mole balance [21]. The model is based on the following assumptions: (i) the cross section of the channel and the washcoat thickness remain constant, (ii) ignores axial diffusion and conduction in the fluid phase, (iii) laminar flow in the channel, (iv) constant physical properties of the gas and solid phases, and (v) ignores heat conduction in the solid phase. 
The experiments to extract the kinetic parameters were conducted at sufficiently low feed temperatures to minimize mass transfer intrusion, and the propylene conversion was kept below $15 \%$. The experiments were conducted in the 200 CPSI monolith with a feed of $\mathrm{C}_{3} \mathrm{H}_{6}=0.3$ vol. $\%, \mathrm{O}_{2}=10$ vol. $\%, \mathrm{~T}_{\mathrm{f}}=152{ }^{\circ} \mathrm{C}$, and $\mathrm{F}_{\mathrm{T}}=11,600 \mathrm{sccm}$. The invasiveness of the probe in this case is mainly a result of its sampling position near the wall. fluid temperatures. Here the probe's invasiveness is mainly a result of its sampling position along the wall of the channel. Fig. $6 a$ and $6 \mathrm{~b}$ report the SpaciMS $(170 \mu \mathrm{m})$ and c-OFDR measured propylene concentration and intrachannel temperature, respectively. The experimental conversion was $13 \%$, while the temperature rise was $30^{\circ} \mathrm{C}$.

The corresponding monolith model predictions are also shown in Fig. 6 in terms of fluid and surface propylene concentrations $\left(\mathrm{C}_{\mathrm{s}}, \mathrm{C}_{\mathrm{f}}\right.$; Fig. 6A) and temperatures $\left(\mathrm{T}_{\mathrm{s}}, \mathrm{T}_{\mathrm{f}}\right.$; Fig. 6B). A reasonably good fit of the data is evident. The experiments indicate that the concentration is essentially bounded between the average bulk and surface concentrations. Here the probe's invasiveness is mainly a result of its sampling position along the channel wall. Fig. 6B shows that the experimental temperature was within $6^{\circ} \mathrm{C}$ of the predicted fluid and surface temperatures, indicating that the model described reasonably well the non-isothermal behavior. The kinetic parameters obtained for the 200 CPSI were used to predict the fluid and surface temperatures.

\section{Figure 6.}

Following this scheme, we estimated the kinetic parameter constants for the 100, 400 and 600 CPSI monolith reactors at low conversion (conversion $<15 \%)$, and low temperature rise $(\Delta \mathrm{T}$ $<40^{\circ} \mathrm{C}$ ). For each monolith a set of experiments was conducted and the parameters estimated. Table 4 reports the estimated kinetic parameters for each monolith while the Supplementary Material provides the plots for the three other monoliths. The estimated value of the pre- 
exponential constant $b_{1}$ for the 400 CPSI monolith are of the order of $10^{17}\left(\mathrm{~mol} / \mathrm{m}^{3} \mathrm{~s}\right)$, which is 100 times larger than of the other monoliths. This difference is attributed to the three-fold higher loading of Pt in the commercial 400 CPSI. The average estimated value of the parameters $\mathrm{b}_{2}$ and $\mathrm{b}_{4}$ for the $\mathrm{C}_{3} \mathrm{H}_{6}$ oxidation were about $\sim 12,000 \mathrm{~K}$ and $\sim-100 \mathrm{~K}$, respectively. For comparison, Voltz et al. [22] reported these values as $11,427 \mathrm{~K}$ and $-361 \mathrm{~K}$ based on experiments in a fixed bed integral reactor containing $\mathrm{Pt} / \mathrm{Al}_{2} \mathrm{O}_{3}$ catalyst. It is noted that the confidence limits for some of the parameters are rather large. This reflects the limited number of points used to estimate the parameters. Obviously, the large confidence limits would preclude their use to use them to simulate the reactor. However, our intent is simply to estimate the reaction time constant (eqn. (12)) in the creation of the $\Delta \mathrm{Z}$ map described next.

\section{Table 4.}

\section{Assessing impact of the probe: $\Delta \mathrm{Z}$ map}

The spatial profiles of propylene concentration and temperature were measured for different feed conditions distributed among these four monoliths and two capillary probes. The objective was to identify and relate trends in the spatially-resolved data to an impact of the capillary probe. We describe below how to assess the probe impact from the relationship between the concentration and temperature profiles.

When a single irreversible reaction occurs in an adiabatic reactor, a linear relationship exists between the fluid temperature rise and the limiting reactant conversion

$$
\Delta T=\frac{(-\Delta H) X C_{f}}{\rho C_{p f}}
$$


Under adiabatic conditions the temperature rise $\Delta \mathrm{T}$ approaches the adiabatic temperature rise at complete conversion of the limiting reactant; i.e., $\Delta \mathrm{T}(\mathrm{X} \rightarrow 1)=\Delta \mathrm{T}_{\mathrm{ad}}$. [Note: If any heat losses occur then Eqn. (14) is no longer valid and the temperature profile may achieve a maximum along the length of the monolith channel.] Under this linear dependence between $\Delta \mathrm{T}$ and $\mathrm{X}$ inferred by Eqn. (14), the reactant concentration profile is essentially a mirror image of the temperature profile. We contend that the SpaciMS capillary probe is non-invasive if the linear dependence is achieved in an experiment. The rationale is that any blockage by the probe would increase the residence time in the channel. As a result, the temperature profile in a neighboring channel containing the c-OFDR fiber will be shifted downstream from the concentration profile. Any deflected flow would increase the flow rate in neighboring channels, which would further shift the temperature profile downstream. Clearly this methodology relies on all channels having identical dimensions, washcoat loading, and activity. Another assumption is that the optical fiber is sufficiently fine so that it has only a negligible effect on the flow in the channel in which it is contained.

A convenient way of assessing the linearity between the conversion and temperature rise is by the metric $\Delta \mathrm{Z}$, defined as the difference between the axial position of the temperature maximum or threshold temperature ( $\left.Z_{T \text { max }}\right)$ measured by the c-OFDR optical fiber, and the axial position of the propylene depletion position $\left(Z_{c=0}\right)$ measured by the SpaciMS probe

$$
\Delta Z=\left.Z\right|_{T \text { max }}-\left.Z\right|_{c=0}
$$

Thus, $\Delta \mathrm{Z} \rightarrow 0$ implies that the SpaciMS probe is non-invasive, while $\Delta \mathrm{Z}>0$ is a result of contributions from the probe's invasive nature and radial sampling when a transverse concentration gradient exists. We showed earlier that the capillary probe samples the surface 
concentration. This in itself is not problematic, but when combined with the fact that the optical fiber measures more closely the fluid temperature in the center of a channel, leads to a non-zero $\Delta \mathrm{Z}$. We illustrate these concepts in more detail below. Finally, it should be mentioned that the error associated with the spatial measurements by the capillary probe and the optical fiber are \pm $0.5 \mathrm{~mm}$ and $\pm 2 \mathrm{~mm}$ respectively. Thus, the experimental error for $\Delta \mathrm{Z}$ is $\pm 2.5 \mathrm{~mm}$.

Fig. 7a shows the results of an experiment in which a feed containing $0.17 \%$ propylene and $10 \% \mathrm{O}_{2}$ was fed at $8,000 \mathrm{sccm}$ at a temperature of $200{ }^{\circ} \mathrm{C}$. The lowest cell density (widest channel) monolith (100 CPSI) and larger probe were used (363 $\mu$ m o.d.). The data show that the concentration and temperature profiles are essentially mirror images of each other and $\Delta \mathrm{Z} \sim 0$. In this experiment, we conclude that the capillary probe is not invasive. Fig. $7 \mathrm{~b}$ is another example in which a hotter gas $\left(\mathrm{T}_{\mathrm{f}}=246^{\circ} \mathrm{C}\right)$ was fed to the $100 \mathrm{CPSI}$ monolith, while employing the smaller capillary probe $(170 \mu \mathrm{m}$ OD). All other feed conditions were the same as in Fig. $7 \mathrm{a}$. A rather large shift between the two profiles is evident in this experiment, with $\Delta \mathrm{Z} \sim 16 \mathrm{~mm}$. We conclude that the large $\Delta \mathrm{Z}$ is due to an invasive sampling arrangement, shorter hydraulic diffusion length and steeper radial concentration gradient.

\section{Figure 7.}

Table 5 lists 37 distinct experiments in terms of the monolith cell density (CPSI), dimensions of the capillary probe $\left(\mathrm{d}_{\mathrm{i}}, \mathrm{d}_{\mathrm{o}} ; \mu \mathrm{m}\right)$, feed gas temperature $\left(\mathrm{T}_{\mathrm{f}} ;{ }^{\circ} \mathrm{C}\right)$ and total volumetric flow rate $\left(\mathrm{F}_{\mathrm{T}} ; \mathrm{sccm}\right)$. Values of $\log (\phi)$, dimensionless propylene depletion point $\left(\mathrm{Z}^{\prime}\right)$ and the invasiveness metric $\Delta \mathrm{Z}$ is also provided. Feed composition of experiments denoted without an asterisk (*) is 0.17 vol. $\% \mathrm{C}_{3} \mathrm{H}_{6}$ and 10 vol. $\% \mathrm{O}_{2}$, while of those denoted with asterisk is $0.3 \mathrm{vol}$. $\% \mathrm{C}_{3} \mathrm{H}_{6}$ and 10 vol. $\% \mathrm{O}_{2}$. A plot of $\Delta \mathrm{Z}$ as a function of a single dimensionless parameter such as 
$\phi$ did not show any obvious trend, such as a monotonic shift from low to high $\Delta \mathrm{Z}$ values upon increasing $\phi$. We tried with limited success to use several other dimensionless groups to identify a coherent correlation of the $\Delta \mathrm{Z}$ data. This suggests that at least one more parameter is needed to correlate the $\Delta \mathrm{Z}$ data.

\section{Table 5 .}

An informative result was achieved with a two-dimensional map of $\Delta \mathrm{Z}$ in the plane of the Z' and $\log (\phi) . Z^{\prime}$ is defined as the dimensionless position of propylene depletion; i.e.

$$
Z^{\prime}=\frac{\left.Z\right|_{C=0}}{L}
$$

where $\mathrm{L}$ is the length of the monolith, such that $0 \leq \mathrm{Z}^{\prime} \leq 1$. Figure shows the $\Delta \mathrm{Z}$ map as a function of $Z^{\prime}$ and $\log (\phi)$. (The map was constructed by Origin $9.0^{\circledR}$ software, using Color Fill Contour Plot feature.) The data points on the $\Delta \mathrm{Z}$ map correspond to the numbers in Table 5. Thus one can interpret the impact of the various operating parameters by referring to Table 5 . The $Z^{\prime}$ axis is divided into three zones; a downstream zone $\left(Z^{\prime}>0.6\right)$, a midstream zone $(0.2<$ $\left.Z^{\prime}<0.6\right)$, and upstream zone $\left(Z^{\prime}<0.2\right)$. The $\log (\phi)$ axis spans values from 1.9 to $\sim 3.9$, or $80<\varphi<$ 7900. As defined earlier, $\phi$ is the ratio of transverse diffusion to reaction time. One reason for the wide range of values is that the measured temperature at the depletion point was used to estimate $\mathrm{k}_{1}$. For small values of $\phi(<1)$ there are no transverse gradients as the diffusion time is smaller than the convection time; for intermediate values of $\phi(1<\phi<100)$ the reaction is moderately transport limited, while for very high values of $\phi(>100)$ the reaction is essentially instantaneous and mass transport limited and has the steepest transverse gradient. 
Figure 8 .

The main $\Delta \mathrm{Z}$ map features are:

- The smallest values of $\Delta \mathrm{Z}(0 \leq \Delta \mathrm{Z} \leq 4)$ occur when propylene is depleted in the downstream zone $\left(Z^{\prime}>0.6\right)$.

- The lone black region occurs for $Z^{\prime}>\sim 0.7$ and $\log (\phi)>\sim 3$.

- In the midstream zone $\left(0.2 \leq Z^{\prime} \leq 0.6\right)$, the $\Delta \mathrm{Z}$ values are moderate to high (4 to $12 \mathrm{~mm}$ ). One exception is the small blue region ( $\Delta \mathrm{Z} \sim 0$ to $4 \mathrm{~mm}$ ) encountered for lower $\phi$ values $(\log (\phi) \sim 1.9-2.1)$

- For most of the upstream zone $\left(Z^{\prime}<0.2\right)$ moderate to significant $\Delta Z$ values are encountered ( $\Delta \mathrm{Z} \sim 4$ to $20 \mathrm{~mm}$ ). This trend is similar to the findings of Morgan et al. [1]. They tested five different reactor setups with various degree of probe's blockage and found that the more invasive nature of the probe was encountered for the smaller reactant concentrations measured in the upstream region.

When the propylene is depleted in the downstream zone, fluid and solid temperatures approach each other and the steady state temperature. The optical fiber senses a temperature bounded by these two values. Earlier we established that the smallest capillary probe measures a concentration that is closer to that of the surface than to that of the bulk. In the absence of a transverse temperature gradient and applying Eq. (14), a nonzero $\Delta \mathrm{Z}$ suggests that the blocking effect is the main cause in this region. Indeed, $\Delta \mathrm{Z} \sim 0$ for the group of Experiments $5-8$, and 16 - 19, all of which involved either the 100 or 200 CPSI monoliths. Their wider channel size was apparently sufficient to prevent any blockage by the capillary. For Experiments $5-8$ in the $\Delta \mathrm{Z}=$ 
0 region correspond to mixtures fed to the 100 CPSI monolith (no blockage). On the other hand, upon decreasing $\phi$ for fixed $Z$ ' $\sim 0.9$, nonzero $\Delta \mathrm{Z}$ values are reported. For example, Experiments 34 and 35 in the blue region were obtained for feed temperatures of $140-160{ }^{\circ} \mathrm{C}$ using the 600 CPSI monolith. Indeed, most of the experiments in this blue region involved the 600 CPSI monolith. The smaller $\phi$ reflects the lack of transverse concentration gradient. The fact that $\Delta \mathrm{Z}>$ 0 suggests that flow blockage is the root cause.

The trends observed in the midstream zone are not as discernible and must have higher values of $\Delta \mathrm{Z}$. In this region, the temperature gradient between the fluid and the surface at the depletion concentration location is small. A careful inspection of Experiment 36 shows that insertion of the probe caused a small but measureable upstream shift in the concentration profile (see Fig. 9A). We conjecture that this upstream shift is not due to flow blockage by the probe but rather to an increase of the external mass transfer rate due to the shorter hydraulic channel length resulting from the presence of the probe. For $\log (\phi)$ values between 2.2 and 3.8 the $\Delta \mathrm{Z}$ map does not provide clear insight about the probe impact. In this zone, steep transverse concentration gradients lead to a large discrepancy between the solid and fluid temperatures. Here the probe's invasiveness is mainly a result of its sampling position along the wall of the channel. This claim deserves some elaboration. The data suggest that the c-OFDR temperature measurement is closer to that of the fluid than of the solid. While the optical fiber rests on the wall of the monolith, most of its surface is exposed to the fluid. Thus, for cases in which the fluid temperature is lower than that of the solid the optical probe may sense a temperature closer to that of the fluid temperature. On the other hand, as we showed in the context of Fig. 5 the SpaciMS measures a concentration close to that of the surface. As a result, at the point of measured propylene depletion the local solid temperature should approach the adiabatic 
temperature rise. But as the temperature measured by the fiber is of the fluid and not the solid, this results in a mismatch between the maximum solid temperature and measured fluid temperature. Finally, it is worth noting that were the fiber probe to measure the solid temperature, one would expect the temperature profile to be qualitatively different. Instead of increasing with distance down the length of the monolith the solid temperature would be hottest near the entrance and decrease along the monolith, eventually approaching the same level as the increasing fluid temperature.

Following this reasoning, one may conclude that a large value of $\phi$ for a fixed value of Z' should result in a large $\Delta Z$. However, a comparison between Experiments 20, 21, and 4 shows the opposite trend; i.e., for essentially at the same depletion location ( $\left.Z^{\prime} \sim 0.2-0.3\right)$, the $\Delta Z$ value obtained in Experiment 4 (reduced concentration gradient) exceeds that obtained in Experiments 20 and 21 in spite the latter experiments had a steeper concentration gradient than in Experiment 4. This unexpected result suggests that the two parameters ( $\varphi$ and Z') are not sufficient to account for all of the $\Delta \mathrm{Z}$ trends. A potential explanation has to do with the fact that Experiments 20 and 21 were obtained for the commercial catalyst (400 CPSI) for which the Pt loading was about three-fold higher than that of the catalyst used in Experiment 4 (100 CPSI monolith). Thus to obtain the same depletion location, the feed temperature in Experiment 4 was necessarily higher $\left(\mathrm{T}_{4, \mathrm{f}}=224{ }^{\circ} \mathrm{C}\right.$ vs. $\mathrm{T}_{20, \mathrm{f}}$ and $\left.\mathrm{T}_{21, \mathrm{f}} \sim{ }^{\circ} 181 \mathrm{C}\right)$ than that in Experiments 20 and 21 in order to achieve the same activity. However, the higher operating temperature led to a complex heat transfer impact such as potential heat losses to the environment and thermal gradient among monolith channels. These thermal effects may contribute to the larger $\Delta \mathrm{Z}$.

In the upstream region $\left(Z^{\prime} \sim 0\right.$ to 0.2$) \Delta Z$ is typically high $(>12 \mathrm{~mm}$ ) with the highest values $(16-20 \mathrm{~mm})$ encountered in a range of $\log (\phi)$ between $\sim 2.8$ and 3.2. The data in this 
zone push the limits of $\Delta \mathrm{Z}$ methodology ability to assess the degree of invasiveness. When the limiting reagent is depleted at catalyst front, the solid temperature is likely hotter than the fluid temperature by 10 's ${ }^{\circ} \mathrm{C}$. For example, Dario et al. [28] used a thermocouple to measure the gas temperature and a pyrometer to measure the solid temperature during the catalytic partial oxidation of methane. They observed that when the hot spot occurred at the entrance, the maximum temperature measured by the pyrometer was higher and located a few millimeters upstream of the maximum temperature measured by a sliding thermocouple. The maximum temperature measured by the pyrometer was $\sim 920{ }^{\circ} \mathrm{C}$ and $\sim 800{ }^{\circ} \mathrm{C}$ as measured by the thermocouple. The large $\Delta Z$ observed in our study is attributed to the above-mentioned heterogeneous effect; i.e. while the optical fiber sensed the fluid temperature the capillary probe measured the surface concentration.

To expand on this point, we inspected Experiment 2 closely (refer to Fig. 9b). In this experiment the most open monolith was used (100 CPSI) together with the smaller of the two probes $\left(d_{o}=170 \mu \mathrm{m}\right)$. At first glance one would think with this probe/monolith combination for which only $2 \%$ of the channel area is blocked by the fiber that the invasiveness of the probe should be minimal, at least from the standpoint of flow blockage. Nevertheless, a rather large $\Delta Z$ of $17 \mathrm{~mm}$ was observed. Obviously, this result is not due to flow blockage. Assuming that some other effect such as nonuniform washcoat deposition is not responsible, the only explanation is the aforementioned heterogeneous effect: the optical fiber sensed the fluid temperature while the capillary probe that measured the surface concentrations.

An additional explanation for large $\Delta \mathrm{Z}$ in the upstream region is that the probe insertion length increases when the depleted concentration location moved upstream. While this effect has 
been discussed in relation to the earlier results obtained for the 100 CPSI monolith (refer to Fig. 2), it may play a role for higher pore density monoliths.

Figure 9.

It is noticed that a small blue region for $Z^{\prime}<0.2$ that exists in which $\Delta \mathrm{Z}$ has a low to moderate value $(4-8 \mathrm{~mm})$. Some insight of the origin of this result is provided by a comparison of experiments 12 and 29. Experiment 29 was conducted with the 600 CPSI monolith and large probe $(363 \mu \mathrm{m})$ at a flow rate of $8000 \mathrm{sccm}$ and feed temperature of $239^{\circ} \mathrm{C}$. The only difference with Experiment 12 is the use of the more open 200 CPSI monolith. The larger $\Delta Z$ obtained for the 600 CPSI monolith $(15 \mathrm{~mm})$ than for the 200 CPSI monolith $(7 \mathrm{~mm})$ suggests a more severe impact of the probe blockage effect for the former.

The $\Delta \mathrm{Z}$ map is a useful for classifying the impact of the SpaciMS capillary probe for a range of operating conditions, monolith structures, operating conditions, and reactor regimes. Depending on the hot zone location inside the reactor, a SpaciMS can be implemented either at the front or the back of the reactor to mitigate the exposure of the tube to high temperature region. Our analysis is limited to conditions leading to complete conversion of the limiting reactant and a back reactor SpaciMS implementation (suction flow is in the same direction as reactive flow). As the c-OFDR measures the fluid rather than solid temperature but the SpaciMS measures the surface rather than the fluid concentration, $\Delta \mathrm{Z}$ is a useful identification of conditions in interpreting data and modeling.

Finally, additional experiments and simulations are needed to provide more detailed information on the conditions under which the probe SpaciMS probe has a minimal invasive impact. 


\section{Conclusions}

The objective of this work is to study the impact of the capillary probe on the accuracy of SpaciMS concentration measurements. To this end, we carried out propylene oxidation on $\mathrm{Pt} / \mathrm{Al}_{2} \mathrm{O}_{3}$ washcoated monoliths with a range of channel densities $(100,200,400$, and $600 \mathrm{CPSI})$, and concentration sampling by probes of two different sizes (170 \& $363 \mu \mathrm{m}$ o.d.). The axial position of the probe did not influence the flow profile in the 100 CPSI monolith channel, nor did it alter the amount of flow shifted to surrounding channels for the 600 CPSI reactors.

We investigated the effect of the probe size on the spatial concentration measurement. The SpaciMS concentration measurement in the conventional 400 CPSI monolith reactor at the relevant space velocity of $12 \mathrm{k} \mathrm{h}^{-1}$ with two capillary probe sizes showed similar profiles. An analytical prediction of the compressible flow in a capillary was used to estimate the amount of flow suction by the probe. We found that in some experiments the suction flow rate was about the same as the flow deflected by these capillaries. These experiments implied that for certain operating conditions, the measurement even with a larger capillary probe may still be accurate, due to compensation of the blockage by the suction.

We developed an experimental methodology to assess the uncertainty and to some extent the impact of the capillary probe to the measured conversion. This methodology can be used to interpret the SpaciMS data, as well as provide guidance for designing SpaciMS configuration for a specific application. This method employed the metric $\Delta \mathrm{Z}$, defined as the difference between the axial position of the temperature maximum and the axial position of the propylene depletion position. $\Delta \mathrm{Z} \rightarrow 0$ implies that the SpaciMS probe is non-invasive, while $\Delta \mathrm{Z}>0$ implies the impact of the probe's invasive nature in combination with sampling when a transverse concentration gradient exists. A systematic experimental study provided the $\Delta \mathrm{Z}$ information for 
the 100, 200, 400, and 600 CPSI catalytic monolith at various conditions. When the limiting reactant was completely consumed at the downstream region of the reactor $(>60 \%$ reactor length), $\Delta \mathrm{Z} \rightarrow 0$ and the SpaciMS concentration measurements shows minimal impact. The invasive impact of the probe cannot be asserted when the reactant concentration depletion occurred at these regions due to the limitation of our temperature measurement technique and the complex interplay of heat and mass transfer occurring at the upstream of the reactor. Additional experimental and simulation studies are conducted and will be reported in the future."

\section{Acknowledgements}

The authors thank the BASF and Corning companies for providing commercial catalyst and various blank density monolith reactors. This work is funded by National Science Foundation (CBET- 1067709). 


\section{References}

[1] K. Morgan, J. Touitou, J.-S. Choi, C. Coney, C. Hardacre, J.A. Pihl, C.E. Stere, M.-Y. Kim, C. Stewart, A. Goguet, W.P. Partridge, Evolution and Enabling Capabilities of Spatially Resolved Techniques for the Characterization of Heterogeneously Catalyzed Reactions, ACS Catalysis 6 (2016) 1356-1381.

[2] J.S. Choi, W.P. Partridge, C.S. Daw, Spatially resolved in situ measurements of transient species breakthrough during cyclic, low-temperature regeneration of a monolithic $\mathrm{Pt} / \mathrm{K} / \mathrm{Al} 2 \mathrm{O} 3 \mathrm{NOx}$ storage-reduction catalyst, Appl Catal a-Gen 293 (2005) 24-40.

[3] J.S. Choi, W.P. Partridge, J.A. Pihl, C.S. Daw, Sulfur and temperature effects on the spatial distribution of reactions inside a lean NOx trap and resulting changes in global performance, Catal Today 136 (2008) 173-182.

[4] S. Shwan, W. Partridge, J.-S. Choi, L. Olsson, Kinetic modeling of NOx storage and reduction using spatially resolved MS measurements, Applied Catalysis B: Environmental 147 (2014) 1028-1041.

[5] M. Li, V.G. Easterling, M.P. Harold, Towards optimal operation of sequential NOx storage and reduction and selective catalytic reduction, Applied Catalysis B: Environmental 184 (2016) 364-380.

[6] G.S. Bugosh, V.G. Easterling, I.A. Rusakova, M.P. Harold, Anomalous steady-state and spatio-temporal features of methane oxidation on $\mathrm{Pt} / \mathrm{Pd} / \mathrm{Al} 2 \mathrm{O} 3$ monolith spanning lean and rich conditions, Applied Catalysis B: Environmental 165 (2015) 68-78.

[7] J. Sa, D.L.A. Fernandes, F. Aiouache, A. Goguet, C. Hardacre, D. Lundie, W. Naeem, W.P. Partridge, C. Stere, SpaciMS: spatial and temporal operando resolution of reactions within catalytic monoliths, Analyst 135 (2010) 2260-2272.

[8] M. Hettel, C. Diehm, B. Torkashvand, O. Deutschmann, Critical evaluation of in situ probe techniques for catalytic honeycomb monoliths, Catal Today 216 (2013) 2-10.

[9] A. Goguet, W.P. Partridge, F. Aiouche, C. Hardacre, K. Morgan, C. Stere, J. Sá, Comment on "The Critical evaluation of in situ probe techniques for catalytic honeycomb monoliths" by Hettel et al, Catal Today 236, Part B (2014) 206-208.

[10] H. Nguyen, M.P. Harold, D. Luss, Optical frequency domain reflectometry measurements of spatio-temporal temperature inside catalytic reactors: Applied to study wrong-way behavior, Chemical Engineering Journal 234 (2013) 312-317.

[11] S. Shrestha, M.P. Harold, K. Kamasamudram, A. Yezerets, Selective oxidation of ammonia on mixed and dual-layer Fe-ZSM-5+Pt/A12O3 monolithic catalysts, Catal Today 231 (2014) 105-115.

[12] H. Nguyen, M.P. Harold, D. Luss, Spatiotemporal behavior of $\mathrm{Pt} / \mathrm{Rh} / \mathrm{CeO} 2 / \mathrm{BaO}$ catalyst during lean-rich cycling, Chem Eng J 262 (2015) 464-477.

[13] S. Bhandarkar, T. Parham, J. Fair, Modeling and Experiments of Compressible Gas Flow through Microcapillary Fill Tubes on Nif Targets, Fusion Sci Technol 59 (2011) 51-57.

[14] F. Sharipov, V. Seleznev, Data on internal rarefied gas flows, J Phys Chem Ref Data 27 (1998) 657-706.

[15] N. Dongari, A. Sharma, F. Durst, Pressure-driven diffusive gas flows in micro-channels: from the Knudsen to the continuum regimes, Microfluid Nanofluid 6 (2009) 679-692. 
[16] H. Gossler, B.L. Kee, H. Zhu, M. Hettel, O. Deutschmann, R.J. Kee, Flow and pressure characteristics in rectangular channels with internal cylindrical bodies, Chemical Engineering Science 149 (2016) 296-305.

[17] S.Y. Joshi, M.P. Harold, V. Balakotaiah, Low-Dimensional Models for Real Time Simulations of Catalytic Monoliths, Aiche J 55 (2009) 1771-1783.

[18] B.M. Shakya, M.P. Harold, V. Balakotaiah, Crystallite-Scale Model for NOx Storage and Reduction on $\mathrm{Pt} / \mathrm{BaO} / \mathrm{Al} 2 \mathrm{O} 3$ : Pt Dispersion Effects on NOx Conversion and Ammonia Selectivity, Catal Today 184 (2012) 27-42.

[19] R. Raj, M.P. Harold, V. Balakotaiah, Steady-state and dynamic hysteresis effects during lean co-oxidation of $\mathrm{CO}$ and $\mathrm{C} 3 \mathrm{H} 6$ over Pt/Al2O3 monolithic catalyst, Chem Eng J 281 (2015) 322-333.

[20] K. Ramanathan, V. Balakotaiah, D.H. West, Light-off criterion and transient analysis of catalytic monoliths, Chem Eng Sci 58 (2003) 1381-1405.

[21] S.Y. Joshi, M.P. Harold, V. Balakotaiah, On the use of internal mass transfer coefficients in modeling of diffusion and reaction in catalytic monoliths, Chem Eng Sci 64 (2009) 4976-4991.

[22] S.E. Voltz, C.R. Morgan, Liederma.D, S.M. Jacob, Kinetic Study of Carbon-Monoxide and Propylene Oxidation on Platinum Catalysts, Ind Eng Chem Prod Rd 12 (1973) 294-301.

[23] R.B. Bird, W.E. Stewart, E.N. Lightfoot, Transport phenomena, Rev. 2nd ed., J. Wiley, New York, 2007.

[24] N. Gupta, V. Balakotaiah, Heat and mass transfer coefficients in catalytic monoliths, Chem Eng Sci 56 (2001) 4771-4786.

[25] N. Wakao, J.M. Smith, Diffusion in catalyst pellets, Chem Eng Sci 17 (1962) 825-834.

[26] G.F. Froment, J. De Wilde, K.B. Bischoff, Chemical reactor analysis and design, 3rd ed., Wiley, Hoboken, N.J., 2011.

[27] S.R. Gundlapally, V. Balakotaiah, Heat and mass transfer correlations and bifurcation analysis of catalytic monoliths with developing flows, Chem Eng Sci 66 (2011) 1879-1892.

[28] L.F. Shampine, M.W. Reichelt, The MATLAB ODE Suite, SIAM Journal on Scientific Computing 18 (1997) 1-22.

[29] P. Kumar, T. Gu, K. Grigoriadis, M. Franchek, V. Balakotaiah, Spatio-temporal dynamics of oxygen storage and release in a three-way catalytic converter, Chem Eng Sci 111 (2014) 180190. 


\section{Nomenclature}

$\langle u\rangle$

$\mathrm{U}_{\mathrm{f}}$

$\mathrm{P}_{\text {in }}\left(\mathrm{P}_{\text {out }}\right)$

$\mathrm{d}_{\mathrm{o}}\left(\mathrm{d}_{\mathrm{i}}\right)$

$\mathrm{Y}_{\mathrm{fm}}$

$F_{T}$

$A_{\Omega}$

$P_{\Omega}$

$R_{\Omega_{1}}\left(R_{2}\right)$

$\mathrm{k}_{\mathrm{mo}}$

$\left\langle Y_{w c}\right\rangle$

$\mathrm{k}_{\mathrm{me}}\left(\mathrm{k}_{\mathrm{mi}}\right)$

$\mathrm{Y}_{\mathrm{s}}$

$\mathrm{C}_{\mathrm{T}}$

$\mathrm{r}_{\mathrm{p}}$

$\mathrm{Sh}_{\mathrm{e}}\left(\mathrm{Sh}_{\mathrm{i}}\right)$

$S h_{i \infty}$

$\mathrm{N}$

S

$\mathrm{T}_{\mathrm{f}}\left(\mathrm{T}_{\mathrm{s}}\right)$

$\mathrm{R}_{\mathrm{m}}$

$\mathrm{R}_{\mathrm{g}}$

$\mathrm{T}_{\text {cap }}$

$\mathrm{D}_{\mathrm{f}, \mathrm{e}}$

$D_{i}^{K n u}\left(\mathrm{D}_{\mathrm{f}, \mathrm{i}}\right)$

$\mathrm{r}_{\mathrm{pore}}$

$\mathrm{M}_{\mathrm{M}}$
Average fluid velocity in the fluid phase $(\mathrm{m} / \mathrm{s})$

Fluid velocity at the capillary tube wall $(\mathrm{m} / \mathrm{s})$

Inlet (outlet) pressure of the capillary tube $(\mathrm{Pa})$

Outer (inner) diameter of the capillary tube (m)

Cup-mixing mole fraction of propylene in fluid phase

Total gas flow rate $(\mathrm{sccm})$

Cross sectional channel area open to flow $\left(\mathrm{m}^{2}\right)$

The wetted perimeter $(\mathrm{m})$

Effective transverse diffusion length for flow (washcoat) (m)

Overall mass transfer coefficient $(\mathrm{m} / \mathrm{s})$

Volume averaged mole fraction of propylene in washcoat

External (Internal) mass transfer coefficient (m/s)

Circumferentially averaged mole fraction at the fluid-washcoat interface

Total concentration in gas phase $\left(\mathrm{mol} . \mathrm{m}^{-3}\right)$

Volumetric reaction rate in the washcoat $\left(\mathrm{mol} / \mathrm{m}^{3}\right.$ washcoat $\left./ \mathrm{s}\right)$

External (Internal) Sherwood number

Asymptoic internal Sherwood number

Number of channels

Side length of a channel (m)

Gas phase (solid phase) temperature (K)

Mass-based gas constant $(\mathrm{J} /(\mathrm{kg} \mathrm{K}))$

Molar-based gas constant $(\mathrm{J} /(\mathrm{mol} \mathrm{K}))$

Isothermal temperature of the capillary tube $(\mathrm{K})$

Diffusivity of species in fluid phase $\left(\mathrm{m}^{2} / \mathrm{s}\right)$

Knudsen diffusion (effective diffusion) of gas in washcoat layer $\left(\mathrm{m}^{2} / \mathrm{s}\right)$

Pore radius $(\mathrm{m})$

Molecular mass $\left(\mathrm{g} \mathrm{mol}^{-1}\right)$ 


$\begin{array}{ll}\mathrm{r}_{\mathrm{i}} & \text { Inner radius of the capillary tube }(\mathrm{m}) \\ \mathrm{M}_{\mathrm{s}} & \text { Mass suction flow rate of the capillary tube }(\mathrm{kg} / \mathrm{s}) \\ \mathrm{h}_{\mathrm{f}} & \text { Heat Transfer Coefficient }\left(\mathrm{W} /\left(\mathrm{m}^{2} . \mathrm{K}\right)\right) \\ N u_{\infty} & \text { Asymptoic Nusselt Number } \\ \mathrm{p} & \text { Transverse mass Peclet number } \\ \mathrm{Le}_{\mathrm{f}} & \text { Lewis number } \\ \mathrm{z} & \text { Dimensionless length } \\ \mathrm{k}_{\mathrm{f}} & \text { Heat conductivity of fluid }(\mathrm{W} /(\mathrm{m} \mathrm{K})) \\ \mathrm{L}\left(\mathrm{L}_{\mathrm{cap}}\right) & \text { Length of monolith reactor }(\text { capillary tube })(\mathrm{m}) \\ \mathrm{C}_{\mathrm{uff}} & \text { Specific heat capacity }\left(\mathrm{J} \cdot \mathrm{kg}^{-1} \cdot \mathrm{K}^{-1}\right) \\ \Delta \mathrm{H} & \text { Heat of reaction }(\mathrm{J} / \mathrm{mol})\end{array}$

Greek letters

$\tau$

$\varepsilon$

$\mu_{\mathrm{f}}$

$\rho_{\mathrm{f}}$

$\tau_{\mathrm{d}}\left(\tau_{\mathrm{r}}\right)$

$\phi$

$\sigma_{\mathrm{AB}}$

$\Omega_{\mathrm{AB}}$

$\phi_{s}$
Tortuosity

Porosity of washcoat

Viscosity of fluid (Pa s)

Density of fluid $\left(\mathrm{kg} / \mathrm{m}^{3}\right)$

Transverse diffusion (reaction) time (s)

Ratio between the transverse diffusion time and the reaction time

Collision integral

Lennard-Jones potential parameter

Thiele modulus 


\section{Appendix A: 1-D Low-Dimensional Model of Catalytic Monolith Reactor}

In this section we describe the reactor model used to simulate the propylene oxidation and with which kinetic parameters are estimated. The values of various model parameters are provided in Table 6. The estimated kinetic parameters in Table 4 and the model predictions in Figure 6 for the 200 CPSI monolith. The corresponding fits for the 100, 400, and 600 CPSI monolith catalysts are provided in Figs. S.1 - S.3 in the Supplementary Material.

\section{Table 6.}

The 1-D low dimensional model is adopted from previous work of Joshi et al. [17, 21]. It comprises a set of differential material and energy balances that are solved through numerical integration.

The steady state gas phase material balance is

$$
\langle u\rangle \frac{d Y_{f m}(z)}{d z}=-\frac{1}{R_{\Omega_{1}}} k_{m o}\left(Y_{f m}(z)-\left\langle Y_{w c}\right\rangle(z)\right) .
$$

The corresponding species balance at the surface and inside the washcoat are

$$
\begin{aligned}
& k_{m e}\left(Y_{f m}(z)-Y_{s}(z)\right)=k_{m i}\left(Y_{s}(z)-Y_{w c}(z)\right) \quad \text { and } \\
& k_{m o} \times\left(Y_{f m}(z)-Y_{w c}(z)\right)+\frac{R_{2}}{C_{\text {Total }}} \times\left(-r_{P}\right)=0,
\end{aligned}
$$

where $Y_{f m}(z), Y_{s}(z)$, and $Y_{w c}(z)$ are the cup mixing mole fractions of propylene in the fluid phase, the circumferentially averaged concentration at the fluid-washcoat interface, and the volume averaged mole fractions in the washcoat respectively. $\mathrm{R}_{2}$ is a washcoat thickness, and $\langle u\rangle$ is the average feed gas velocity per channel. The temperature dependent factor $\left(T_{\mathrm{f}}\right.$ (z)/273.15) accounts for the gas expansion at various fluid temperatures. The overall mass transfer coefficient is given by

$$
\langle u\rangle=\frac{F_{T}}{N \times S^{2}} \times\left(\frac{T_{f}(z)}{273.15}\right) .
$$




$$
\frac{1}{k_{m o}}=\frac{1}{k_{m i}}+\frac{1}{k_{m e}}
$$

where $\mathrm{k}_{\mathrm{me}}, \mathrm{k}_{\mathrm{mi}}$, and $\mathrm{k}_{\mathrm{mo}}$ are the external, internal and overall mass transfer coefficients, respectively. The external and internal mass transfer coefficients are defined as

$$
\begin{aligned}
& k_{m e}=\frac{D_{f, e} \times S h_{e}}{4 R_{\Omega_{1}}} \text { and } \\
& k_{m i}=\frac{D_{f, i} \times S h_{i}}{R_{\Omega_{2}}},
\end{aligned}
$$

where $D_{f, e}$ and $D_{f, i}$ are the fluid phase diffusivity and the effective washcoat diffusivity of propylene, respectively. We used the Chapman-Enskog's formula [23] to compute the propylene diffusivity in the fluid phase (Argon as a carrier gas), over the temperature range of $300-900 \mathrm{~K}$,

$$
D_{f, e}=0.0018583 \frac{\sqrt{T_{f}^{3}\left(\frac{1}{M_{A}}+\frac{1}{M_{B}}\right)}}{P \cdot \sigma_{A B}^{2} \cdot \Omega_{A B}} .
$$

$D_{f}, T_{f}, M, \sigma_{A B}$ and $\Omega_{A B}$ in Eq. (24), are the bulk diffusion coefficient, the fluid temperature, molecular weight, collision integral, and Lennard-Jones potential parameters, respectively. The bulk diffusion temperature dependence is $T^{1.5}$.For the sake of simplicity, Eq. (24) is reduced to the more convenient form [19]

$$
D_{f, e}=4.237 \times 10^{-6} \times T_{f}^{1.7844} \mathrm{~cm}^{2} / s .
$$

The value of the external Sherwood number, $\mathrm{Sh}_{\mathrm{e}}$, is reported by Gupta et.al [24]. For a fully developed flow in a rounded square channel and small value of the transverse mass Peclet number $\left(P=\frac{\langle u\rangle R^{2} \Omega_{1}}{L D_{f}} \approx 10^{-3}-10^{-2}\right)$, the constant value of $S h_{e}=\frac{48}{11}$ is used. 
Two types of diffusion contribute to mass transport in the monolith washcoat: volume (molecular) diffusion, and Knudsen diffusion, predicted by Eq. (26) and Eq. (27) respectively.

$$
\begin{aligned}
& D_{i}^{n}=0.0018583 \frac{\sqrt{T_{s}^{3}\left(\frac{1}{M_{A}}+\frac{1}{M_{B}}\right)}}{P . \sigma_{A B}^{2} \cdot \Omega_{A B}} \text { and } \\
& D_{i}^{K}=\frac{2}{3} r \times \sqrt{\frac{8 R^{g} T_{s}}{\pi M_{M}}} .
\end{aligned}
$$

$D_{i}^{K}$ is the Knudsen diffusion coefficient, $\mathrm{r}$ is pore radius, and $\mathrm{R}_{\mathrm{g}}$ is the gas constant. In a porous catalytic washcoat, there are both macropores $(\mathrm{r} \approx 100-500 \mathrm{~nm})$ between the support material particles (i.e., $\gamma-\mathrm{Al}_{2} \mathrm{O}_{3}$, zeolites, ceria...), and small meso or micropores $(\mathrm{r} \approx 3-6 \mathrm{~nm})$ among the catalytic particles. The two most popular effective diffusion models are the random-pore model [25], and the mean transport-pore model by Froment and Bischoff [26]. The latter uses one characteristic pore size and correction factors such as tortuosity $(\tau)$ and porosity $(\varepsilon)$. The tortuosity accounts for the geometrical deviation between straight cylindrical pores and the actual pore length, while porosity is a fraction of the void volume to the washcoat. We used the mean transport pore approach in our simulations. Using the resistance-in series model (Bosanquet's equation), the effective diffusion coefficient in the washcoat is

$$
\frac{1}{D_{f, i}}=\frac{\tau}{\varepsilon}\left(\frac{1}{D_{i}^{v o l}}+\frac{1}{D_{i}^{k n u}}\right)
$$

The internal Sherwood number is evaluated as a function of the Thiele modulus:

$$
S h_{i}=S h_{i \infty}+\frac{\Lambda \phi_{s}^{2}}{1+\Lambda \phi_{s}}
$$


here $S h_{i \infty}$ is the asymptotic internal Sherwood number, obtained in the limit of slow reaction. The constant $\Lambda$ depends on washcoat geometry ; for the case of a square channel with a rounded square flow area, $S h_{i \infty}$ and $\Lambda$ are 2.65 and 0.58 , respectively [21]. The Thiele modulus is defined as

$$
\phi^{2}{ }_{s}=\frac{\tau_{d, w}}{\tau_{r}}=\frac{\frac{R_{2}^{2}}{D_{f, i}}}{\left(\frac{\left.r_{c_{3} H_{6}}\right|_{\text {suffoce }}}{Y_{s} \times c_{\text {Toul }}}\right)^{-1}},
$$

where $R_{2}$ is the washcoat thickness, $D_{f, i}$ is the internal washcoat diffusivity computed by Eq. (25).

The energy balance in the fluid phase is

$$
\langle u\rangle \rho_{f} C p_{f} \frac{d T_{f}}{d z}+\frac{h_{f}(z)}{R_{\Omega_{1}}}\left(T_{f}-T_{s}\right)=0 .
$$

Here, $\mathrm{T}_{\mathrm{f}}$ and $\mathrm{T}_{\mathrm{s}}$ are the fluid and solid temperatures, respectively. $\rho_{f}$ and $\mathrm{C}_{\mathrm{pf}}$ are the density and specific heat capacity of the fluid phase. The local heat transfer coefficient, $\mathrm{h}_{\mathrm{f}}$, is calculated using the Nusselt number $(\mathrm{Nu})$ correlation

$$
h_{f}(z)=\frac{N u(z) k_{f}}{4 R_{\Omega_{1}}} .
$$

The position dependent Nusselt number $(\mathrm{Nu})$ is calculated by [27] 


$$
N u=N u_{\infty}+\frac{0.272\left(\frac{p}{z^{*} L e_{f}}\right)}{1+0.083\left(\frac{p}{z^{*} L e_{f}}\right)^{2 / 3}},
$$

where $z^{*}=z / L$ is the dimensionless length. For a rounded square channel, $N u_{\infty}=3.2 . \mathrm{Le}_{\mathrm{f}}$ and $\mathrm{p}$ are the Lewis fluid and transverse mass Peclet numbers. These quantities are calculated as

$$
\begin{aligned}
& L e_{f}=\frac{k_{f}}{\rho_{f} C p_{f} D_{f, e}} \text { and } \\
& p=\frac{R_{\Omega_{1}}^{2}\langle u\rangle}{L D_{f, e}} .
\end{aligned}
$$

The energy balance for the solid phase is

$$
h_{f}\left(T_{f}-T_{s}\right)+R_{2} \times r_{P} \times(-\Delta H)=0 .
$$

The solid and fluid temperatures were measured close at the centerline channel. Thus, the assumption of adiabatic is reasonable. In addition, heat conduction along the capillary tube is negligible for the steady state profile.

The initial conditions are

$$
\begin{aligned}
& Y_{f m}(z=0)=Y_{f m, 0}, \mathrm{~T}_{\mathrm{f}}(z=0)=T_{f 0}, T_{s}(z=0)=T_{s 0} \text { and } \\
& \left.\frac{\partial T_{s}}{\partial x}\right|_{z=0}=0 .
\end{aligned}
$$

The system of equations was solved using the BDF method (Backward differentiation formulae), which is implemented in ode15i subroutine (part of the Matlab ${ }^{\oplus}$ ODE suite [28]). The ode15i solver can simultaneously adjust both the order of the BDF, the step-size, and maintain 
the local error under control. The solving time is of the order of a second on an i5-4300U processor computer. This is effective for finding the reaction kinetic parameters where several iterations of solving the model are needed for parameter fitting. It is noted that inclusion of a heat conduction term in the enthalpy equation for the solid phase (Eq. 36) results in a second order differential equation, requiring solution of BVP (boundary value problem). In that scenario, the preferred method is to solve the transient model, which is described by an ordinary time dependent differential equation, from the start-up of the experiment until converging to a steady state. The solving methodology used is the method of lines. A drawback of this transient approach is that computing the Thiele modulus (Eq. (30)) required knowledge of the surface concentration. Most published papers used an approximation that the fluid concentration was close to the surface concentration, and compute the Thiele modulus at the fluid concentration [29]. This assumption may be adequate for high density monolith reactors (400 and 600 CPSI), but may not be adequate for the 100 and 200 CPSI monolith as due to the large hydraulic diameter, the fluid (bulk) concentration can differ from the surface concentration. 


\section{Appendix B: Estimation of the Suction Flow}

The Dongari's prediction of the suction mass flow rate is [15]:

$$
M_{s}=\frac{\pi \times r_{i}^{4} \times P_{\text {out }}^{2}}{16 \mu L_{\text {cap }} R T_{\text {cap }}}\left[\left(\frac{P_{\text {in }}}{P_{\text {out }}}\right)^{2}-1\right]+\frac{\mu \pi r_{i}^{2}}{L_{\text {cap }}} \ln \left(\frac{P_{\text {in }}}{P_{\text {out }}}\right)
$$

where $M_{s}$ is a mass suction flow rate $(\mathrm{kg} / \mathrm{s}), \mathrm{L}_{\text {cap }}$ the length of the capillary tube $(\mathrm{m}), \mathrm{T}_{\text {cap }}$ the isothermal temperature of the capillary tube, $R$ the mass-basis gas constant $(\mathrm{J} /(\mathrm{kg} \mathrm{K}))$, and $\mathrm{P}_{\text {in }}$ and $\mathrm{P}_{\text {out }}$ are the inlet and outlet pressures of the capillary, respectively $(\mathrm{Pa})$. For a small pressure drop, $\mathrm{P}_{\text {in }} \approx \mathrm{P}_{\text {out }}$, Eq. (39) reduces to the Hagen-Poiseuille equation for incompressible Newtonian fluid. For a large pressure drop $\left(\mathrm{P}_{\text {in }}>>\mathrm{P}_{\text {out }}, \mathrm{P}_{\text {out }} \approx 0\right)$, the convective term (first term in Eq. (39)) dominates. In this case, the mass suction flow rate is half of that predicted by the HagenPoiseuille's equation.

$$
M_{s}=\frac{\pi \times r_{i}^{4}}{16 \mu L_{c a p} R T_{c a p}}\left[P_{i n}^{2}\right]
$$

Bernoulli's equation is used to estimate inlet pressure of the capillary tube:

$$
P_{a t m}+\frac{1}{2} \rho v_{1}^{2}=P_{\text {in }}+\frac{1}{2} \rho\langle u\rangle^{2}
$$

where $\mathrm{P}_{\mathrm{atm}}$ is an atmospheric pressure $(\mathrm{Pa}), \rho$ fluid density $\left(=\frac{P_{\text {in }}}{R_{\text {ideal }} \times T}\right), v_{1} \approx 0 \mathrm{~m} / \mathrm{s},\langle u\rangle$ is the linear velocity in the monolith channel $\left(\langle u\rangle=\frac{F_{T}}{N \times S^{2}}\right)$. Inserting these values into Eq. (41) yields

$$
P_{a t m}=P_{\text {in }}+\frac{1}{2}\left(\frac{P_{\text {in }}}{R_{\text {ideal }} \times T}\right) \times\left[\frac{F_{T}}{N \times S^{2}}\right]^{2}
$$

Substitution of Eq. (42) into Eq. (40) gives 


$$
M_{s}=\frac{\pi \times r_{i}^{4}}{16 \mu L_{c a p} R_{\text {ideal }} T_{\text {cap }}} \times\left[\frac{P_{a t m}}{1+\frac{F_{T}{ }^{2}}{2 R_{\text {ideal }} \times T \times N^{2} \times S^{4}}}\right]^{2}
$$




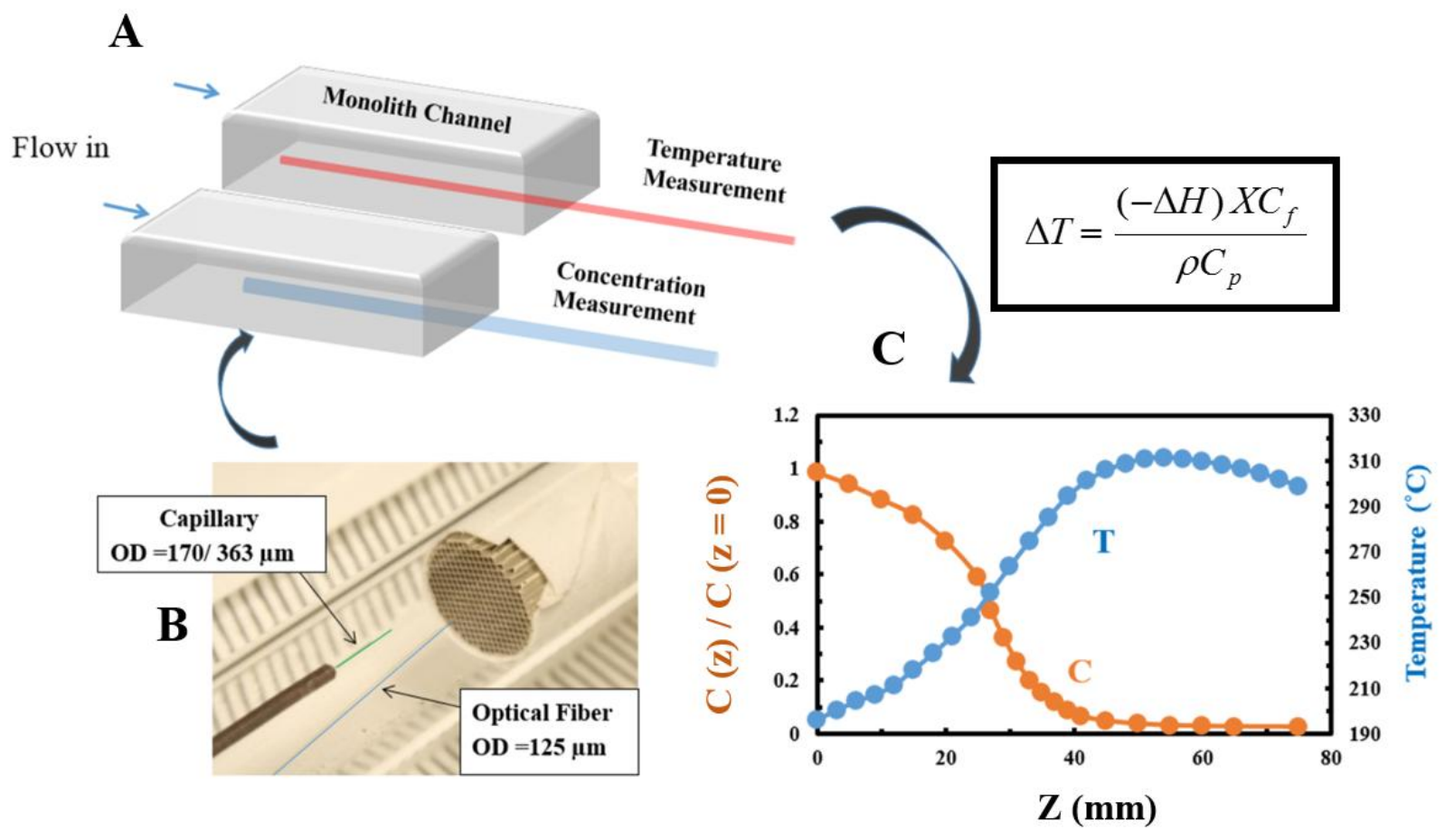

Fig. 1. (A) Schematic of the pair of monolith channels containing the SpaciMS capillary probe and c-OFDR fiber. The species concentration profiles are measured with the SpaciMS. In an adjacent channel the temperature profile is measured with the optical fiber. (B) Photograph of the front face of the monolith showing the capillary probe and optical fiber. (C) Example concentration and temperature profiles for propylene oxidation $\left(0.17\right.$ vol. $\left.\% \mathrm{C}_{3} \mathrm{H}_{6}, 10 \% \mathrm{O}_{2}\right)$ carried out at a space velocity of $17400 \mathrm{hr}^{-1}$ and feed temperature of $195^{\circ} \mathrm{C}$ using the probe diameter of $363 \mu \mathrm{m}$ in a $100 \mathrm{CPSI}$ monolith reactor. A linear relation exists between the axial temperature rise $(\Delta T)$ and propylene conversion $(\mathrm{X})$ as shown by the inset formula. 


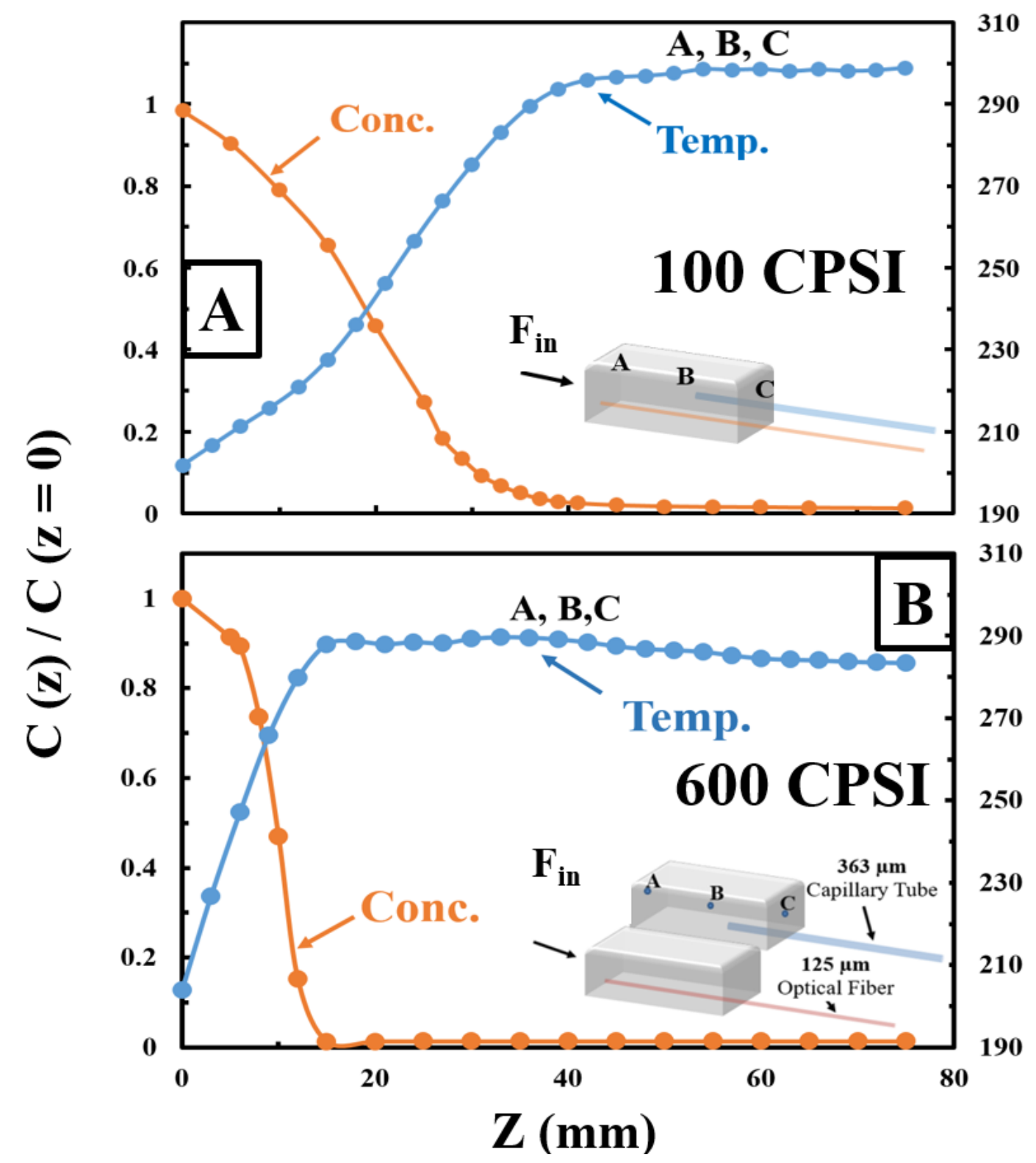

Fig. 2. Spatial temperature and concentration profiles of propylene oxidation $\left(0.17\right.$ vol. $\% \mathrm{C}_{3} \mathrm{H}_{6}$, 10 vol. $\left.\% \mathrm{O}_{2}\right)$ at the total flow rate of $8000 \mathrm{sccm}$ are measured with capillary $\left(\mathrm{d}_{\mathrm{o}}=363 \mu \mathrm{m}\right)$ and optical fiber $\left(\mathrm{d}_{\mathrm{f}}=125 \mu \mathrm{m}\right)$ on (A) $100 \mathrm{CPSI}$, and (B) 600 CPSI monolith reactor. 


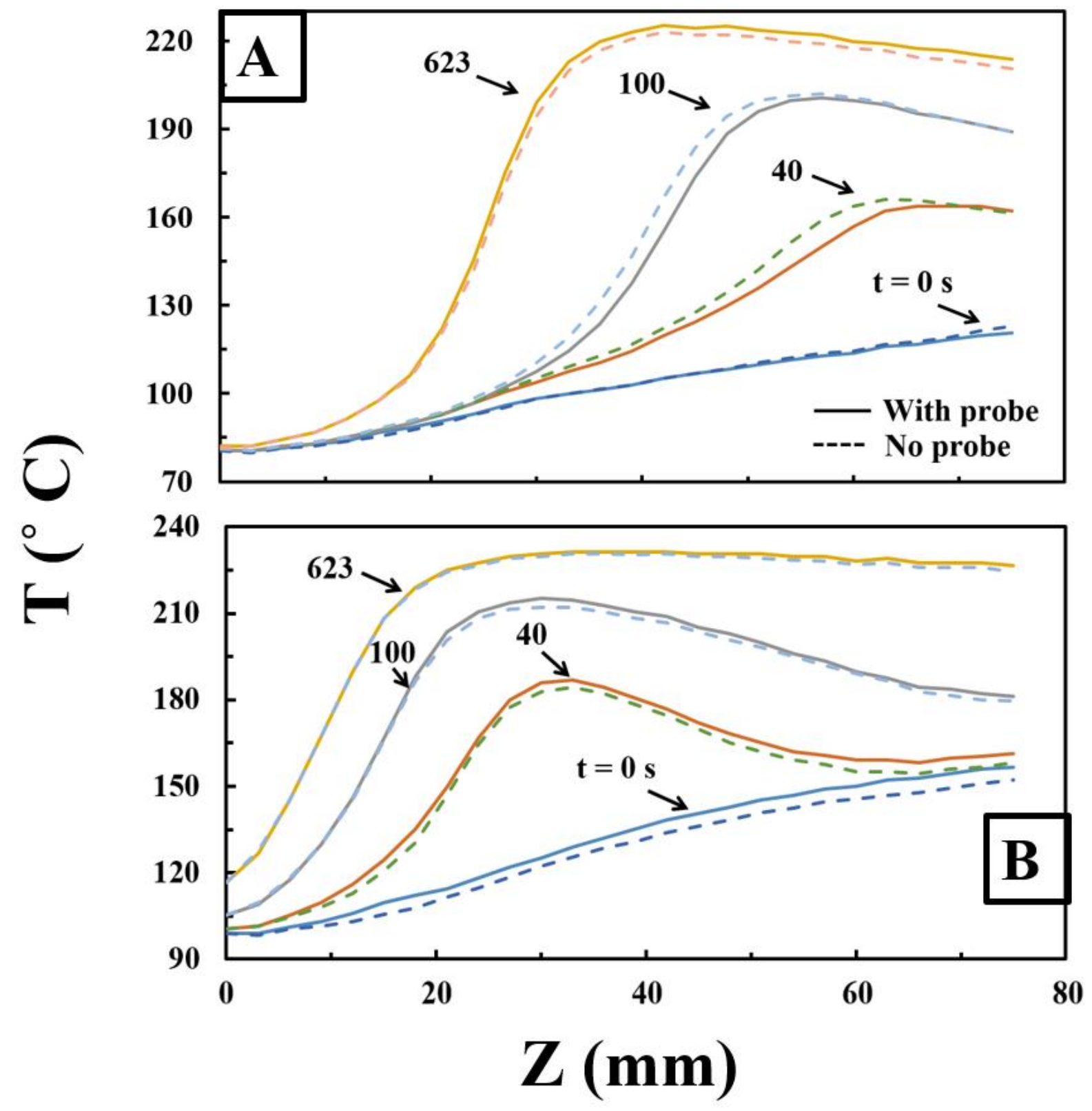

Fig. 3. Transient temperature profiles were reported for the case capillary probe $\left(d_{o}=363 \mu \mathrm{m}\right)$ and 400 CPSI monolith at the inlet (solid line), and case where no probe inside the channel (dash line). The optical fiber and the capillary tube are in the same channel. The gas mixture was 0.17 vol. $\% \mathrm{C}_{3} \mathrm{H}_{6}, 10$ vol. $\% \mathrm{O}_{2}$ and $\mathrm{F}_{\mathrm{T}}=8000 \mathrm{sccm}$ at $(\mathrm{A}) \mathrm{T}_{\mathrm{f}}=81^{\circ} \mathrm{C}$ and $(\mathrm{B}) \mathrm{T}_{\mathrm{f}}=101^{\circ} \mathrm{C}$. 

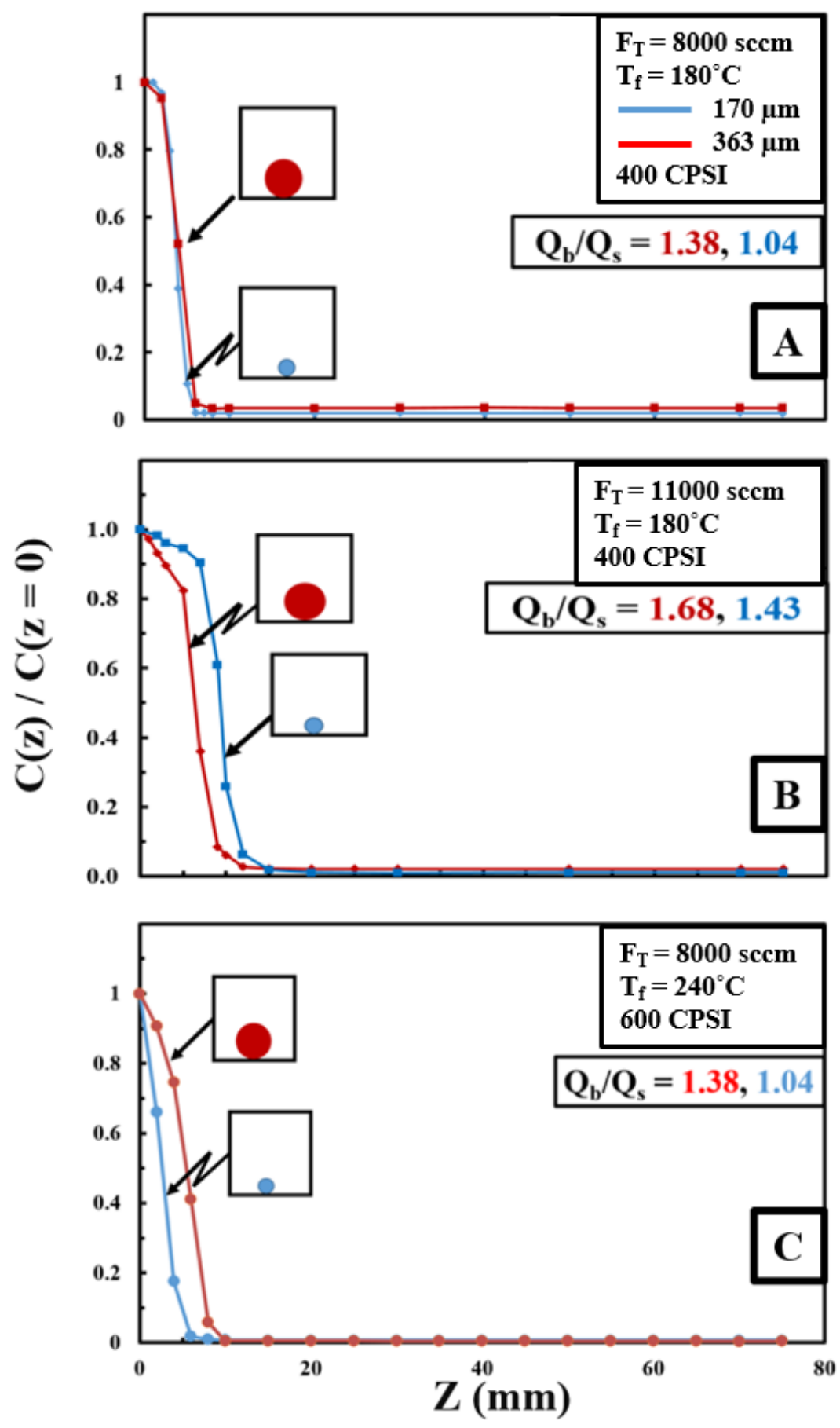

Fig. 4. The propylene concentration profiles were measured by two different probe sizes for a mixture of 0.17 vol. $\% \mathrm{C}_{3} \mathrm{H}_{6}$ and 10 vol. $\% \mathrm{O}_{2}$ at $\mathrm{T}_{\mathrm{f}}=180^{\circ} \mathrm{C}$, and $\mathrm{F}_{\mathrm{T}}=8,000 \mathrm{sccm}$ in a $400 \mathrm{CPSI}$ monolith reactor. 


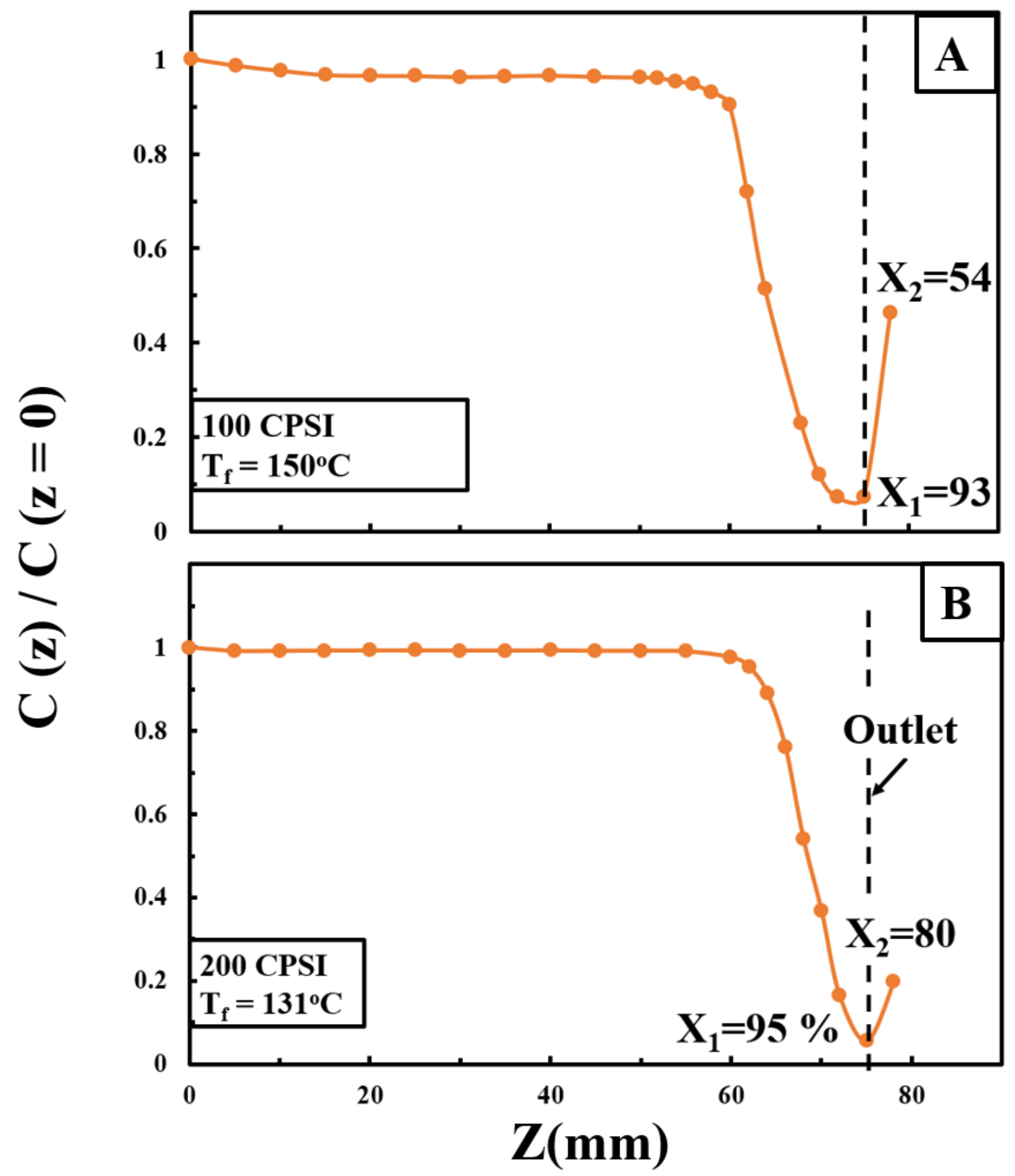

Fig. 5 The propylene concentration profiles were measured by the $170 \mu \mathrm{m}$ capillary probe for a mixture of $0.3 \mathrm{vol} . \% \mathrm{C}_{3} \mathrm{H}_{6}$ and $10 \mathrm{vol} . \% \mathrm{O}_{2}$ at $\mathrm{F}_{\mathrm{T}}=12,000 \mathrm{sccm}$ in (A) $100 \mathrm{CPSI}$, and (B) 200 CPSI monolith reactor. 

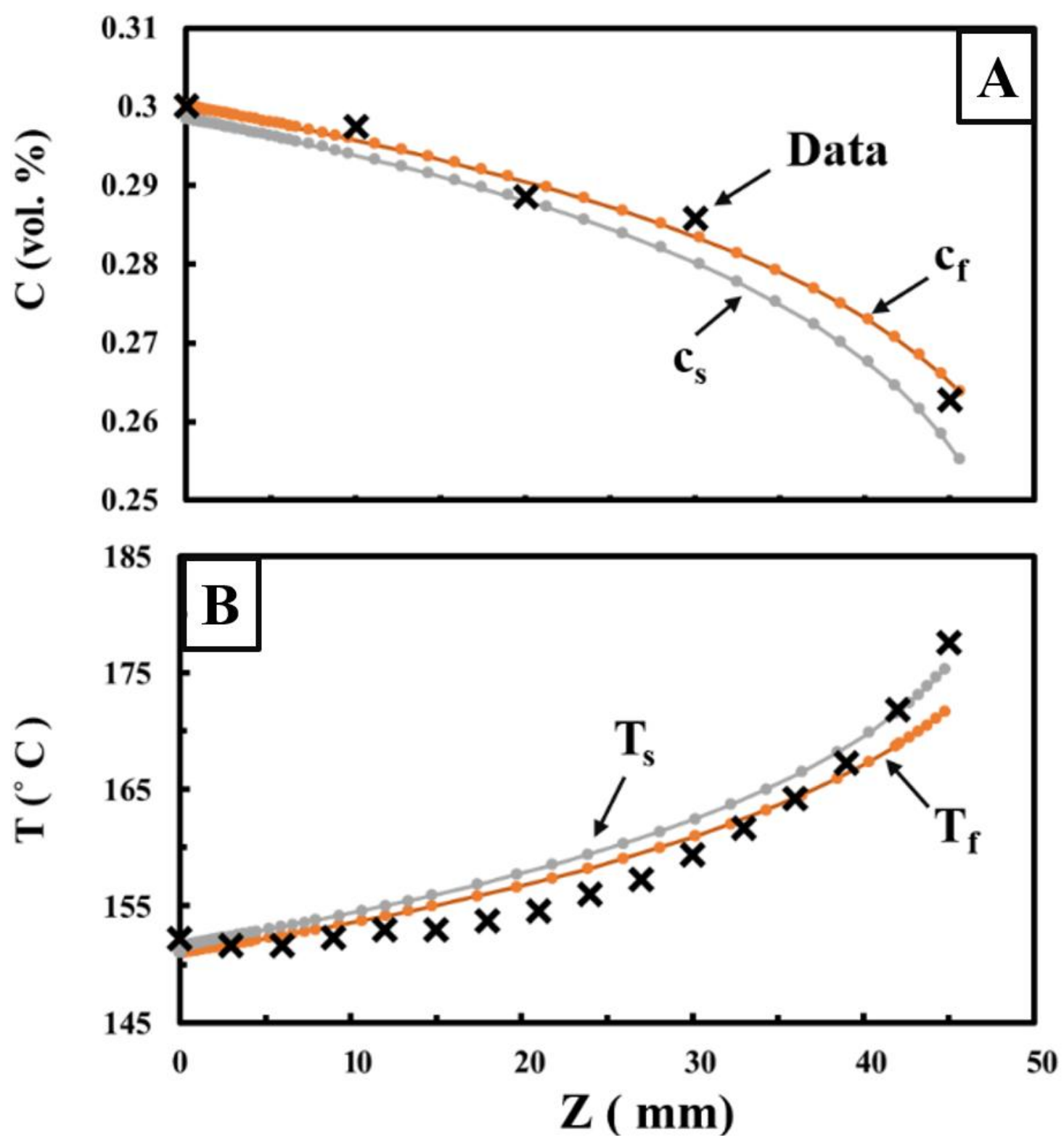

Fig. 6. Fitted spatial concentration and temperature profiles during propylene oxidation. The gray (orange) curves are surface and fluid, respectively. The experiment was conducted in the 200 CPSI monolith reactor $\left(\mathrm{C}_{3} \mathrm{H}_{6}=0.3\right.$ vol. $\%, \mathrm{O}_{2}=10$ vol. $\left.\%, \mathrm{~T}_{\mathrm{f}}=152{ }^{\circ} \mathrm{C}, \mathrm{F}_{\mathrm{T}}=11,600 \mathrm{sccm}\right)$. The intra channel concentration was measured with capillary probe $(\mathrm{O} . \mathrm{D}=170 \mu \mathrm{m})$. $(\mathrm{x})$ is the experimental data, $\mathrm{C}_{\mathrm{f}}, \mathrm{C}_{\mathrm{s}}, \mathrm{T}_{\mathrm{s}}, \mathrm{T}_{\mathrm{f}}$ are computed by the model. 


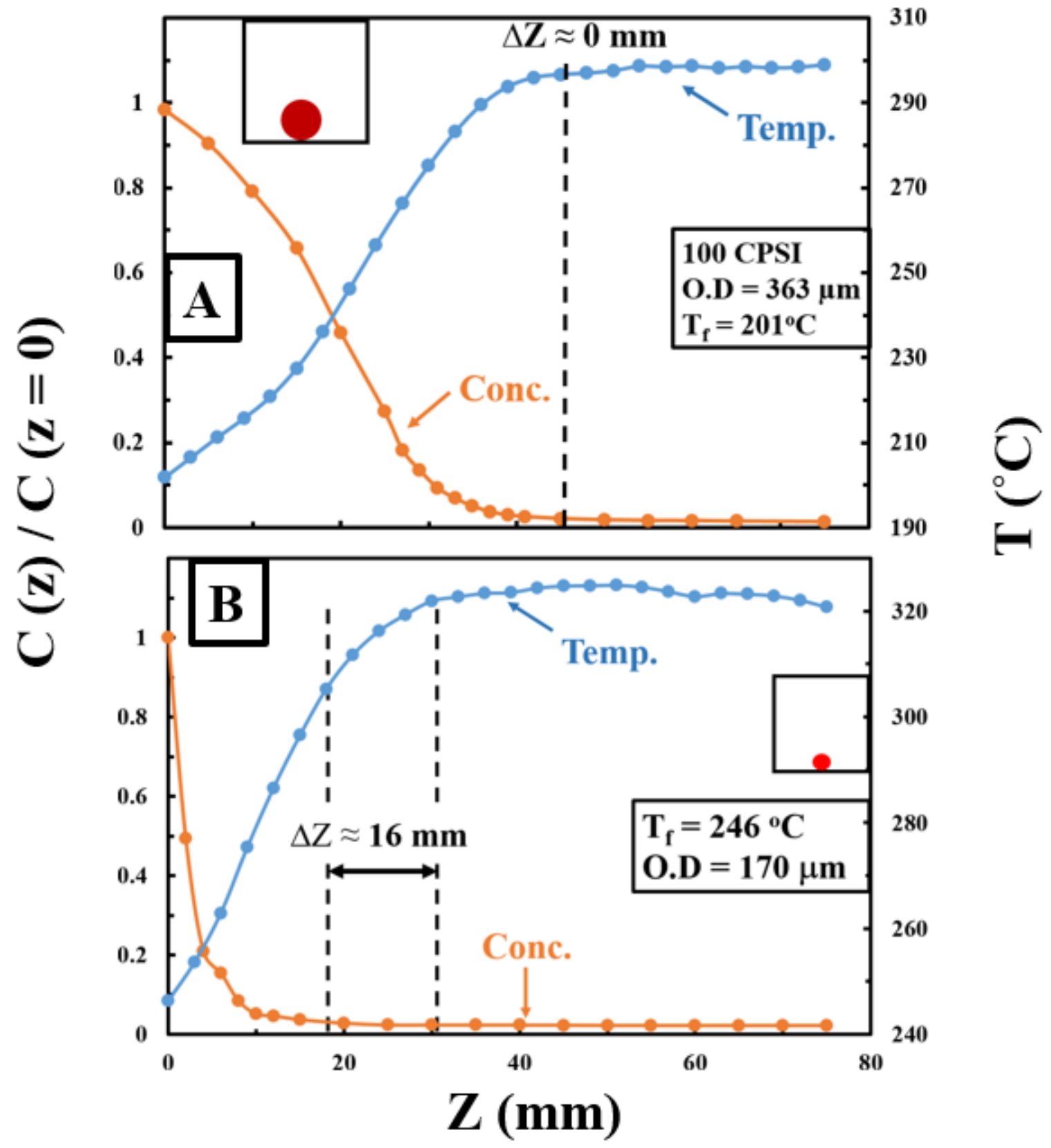

Fig. 7. Measured propylene concentration and temperature profiles for two cases in which a gas containing 0.17 vol. $\% \mathrm{C}_{3} \mathrm{H}_{6}$ and 10 vol. $\% \mathrm{O}_{2}$ is fed at 8,000 sccm to 100 CPSI monolith. Other conditions are: (A) $363 \mu \mathrm{m}$ O.D. probe, $\mathrm{T}_{\mathrm{f}}=201^{\circ} \mathrm{C}$, (B) $170 \mu \mathrm{m}$ O.D. probe, $\mathrm{T}_{\mathrm{f}}=246^{\circ} \mathrm{C}$. 

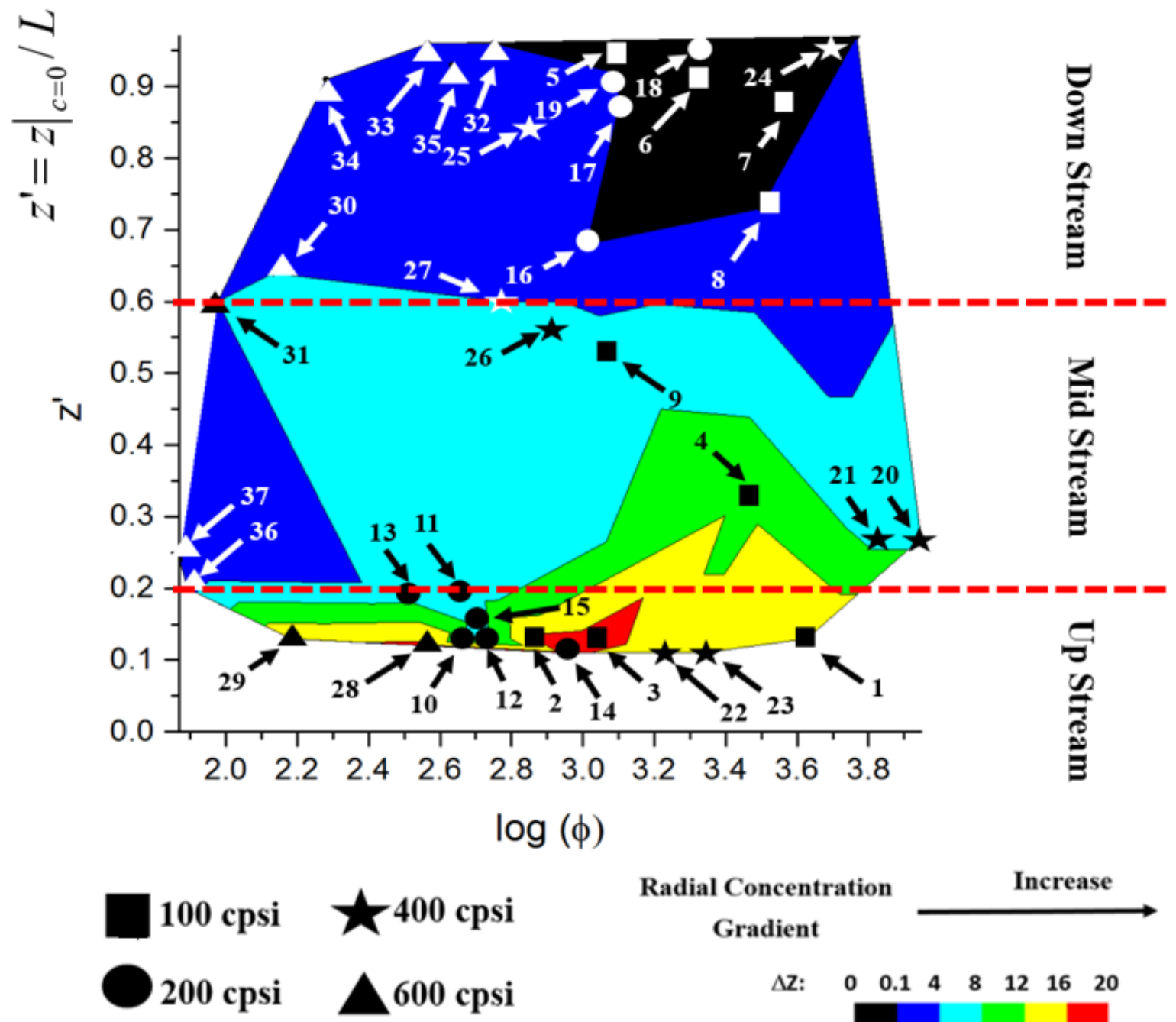

Radial Concentration

Increase Gradient

$\Delta Z: \quad \begin{array}{lllllll}0 & 0.1 & 4 & 8 & 12 & 16 & 20\end{array}$

Fig. 8. $\Delta Z$ map in the plane of $Z^{\prime}$ vs. $\log (\phi)$. The data points in the map correspond to the individual experiments (refer to Table 4 for details). 


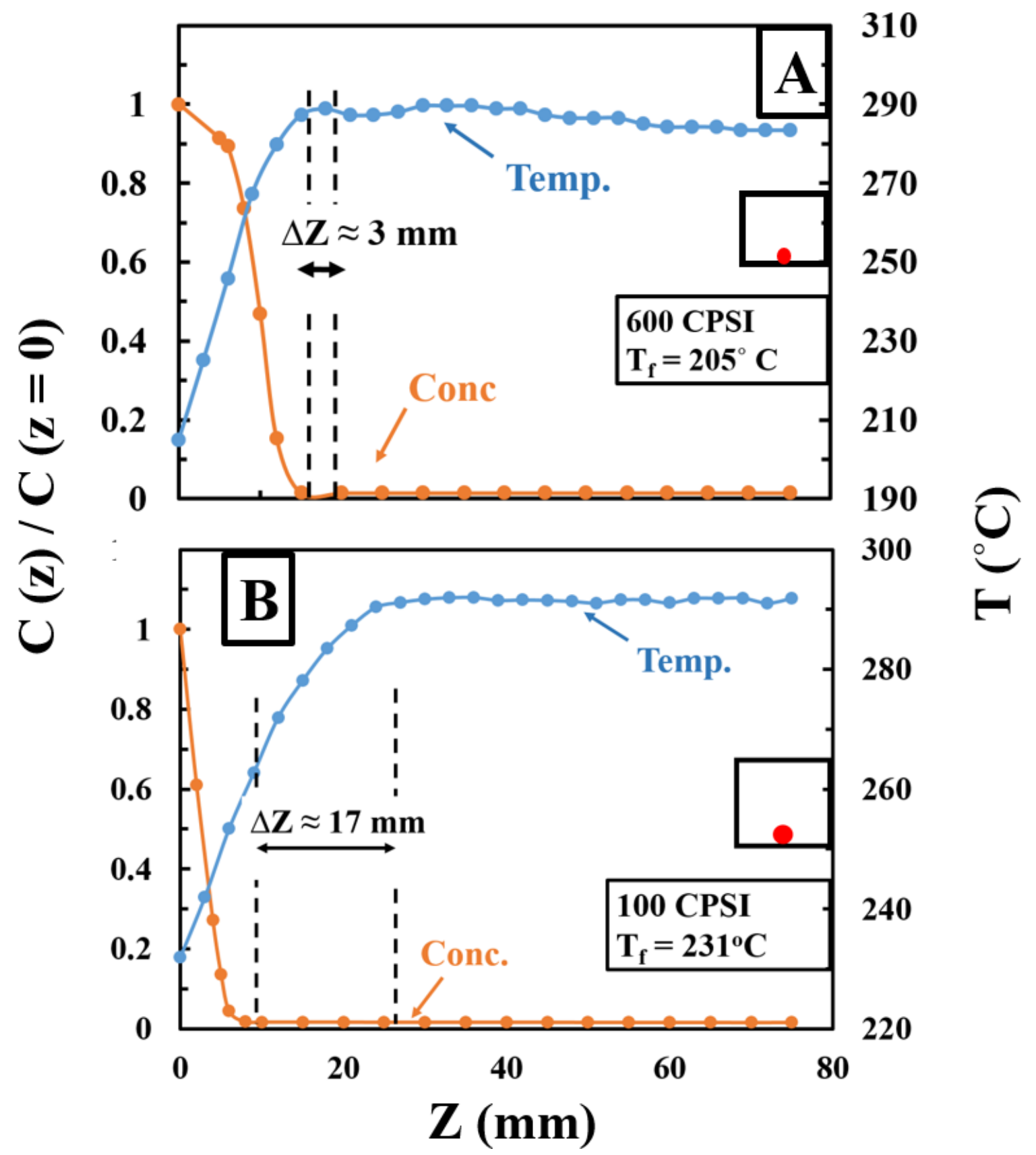

Fig. 9. Measured propylene concentration and temperature profiles using the 170 $\mu \mathrm{m}$ O.D. probe for gas containing 0.17 vol. $\% \mathrm{C}_{3} \mathrm{H}_{6}$ and 10 vol. $\% \mathrm{O}_{2}$ is fed at $8,000 \mathrm{sccm}$ at (A) $205 \mathrm{C}$ to $600 \mathrm{CPSI}$, and (B) $231^{\circ} \mathrm{C}$ to $100 \mathrm{CPSI}$ monolith. 
Table 1. The structural characteristics of various CPSI monolith reactors.

\begin{tabular}{|c|c|c|c|c|}
\hline CPSI & $\mathbf{1 0 0}$ & $\mathbf{2 0 0}$ & $\mathbf{4 0 0}$ & $\mathbf{6 0 0}$ \\
\hline Pt Loading $\left(\mathrm{g} / \mathrm{ft}^{3}\right)$ & 23.8 & 23.8 & 96 & 23.8 \\
\hline Number of Channels $(\mathrm{N})$ & 78 & 157 & 314 & 471 \\
\hline Channel size $[=] \mathrm{mm}$ & 2.54 & 1.80 & 1.27 & 1.04 \\
\hline Washcoat thickness $\left(\mathrm{R}_{2}\right)[=] \mu \mathrm{m}$ & 47 & 35 & 25 & 20 \\
\hline
\end{tabular}

Table 2. Parameters used in the Dongari model.

\section{Constant}

$\mathbf{L}_{\text {cap }}$

$\mu$

$\mathbf{R}$

$\mathbf{P}_{\text {in }}$

$\mathbf{P}_{\text {out }}$

$\mathbf{T}$

\section{Values}

\section{$1.524 \mathrm{~m}$}

$2.09 \times 10^{-5}(\mathrm{~Pa} . \mathrm{s})$

$208(\mathrm{~J} /(\mathrm{kg} . \mathrm{K}))$

$1.01 \times 10^{5}(\mathrm{~Pa})$

$4.0 \times 10^{-6}(\mathrm{~Pa})$

$453.15 \mathrm{~K}$ 
Table 3. The total flow rate is fixed at $8000 \mathrm{sccm}$. The volumetric flow rate per channel in the case of no probe presence $\left(\mathrm{Q}_{\text {ref }}\right)$, and with the probe presence (blocked flow, $\mathrm{Q}_{\mathrm{b}}$, and suction flow, $\mathrm{Q}_{\mathrm{s}}$ ) are tabulated.

\begin{tabular}{cccccccccc}
\hline & $\mathbf{C P S I}$ & $\begin{array}{c}\text { OD } \\
(\boldsymbol{\mu m})\end{array}$ & $\begin{array}{c}\mathbf{I D} \\
(\boldsymbol{\mu m})\end{array}$ & $\begin{array}{c}\mathbf{\%} \\
\mathbf{O} \mathbf{m}\end{array}$ & $\begin{array}{c}\# \\
\text { Channels }\end{array}$ & $\begin{array}{c}\mathbf{Q}_{\text {ref }} \\
(\mathbf{s c c m})\end{array}$ & $\begin{array}{c}\mathbf{Q}_{\mathbf{b}} \\
(\mathbf{s c c m})\end{array}$ & $\begin{array}{c}\mathbf{Q}_{\mathbf{s}} \\
(\mathbf{s c c m})\end{array}$ & $\mathbf{Q}_{\mathbf{b}} / \mathbf{Q}_{\mathbf{s}}$ \\
\hline $\mathbf{1}$ & 100 & 170 & 110 & 0.35 & 78 & 102.6 & 0.36 & 0.34 & 1.05 \\
$\mathbf{2}$ & 100 & 363 & 150 & 1.6 & 78 & 102.6 & 1.64 & 1.19 & 1.38 \\
$\mathbf{3}$ & 200 & 170 & 110 & 0.7 & 157 & 51.0 & 0.36 & 0.34 & 1.04 \\
$\mathbf{4}$ & 200 & 363 & 150 & 3.21 & 157 & 51.0 & 1.64 & 1.19 & 1.38 \\
$\mathbf{5}$ & 400 & 363 & 150 & 6.42 & 314 & 25.5 & 1.64 & 1.19 & 1.38 \\
$\mathbf{6}$ & 400 & 170 & 110 & 1.41 & 314 & 25.5 & 0.36 & 0.34 & 1.04 \\
$\mathbf{7}$ & 600 & 170 & 110 & 2.11 & 471 & 17.0 & 0.36 & 0.34 & 1.04 \\
$\mathbf{8}$ & 600 & 363 & 150 & 9.62 & 471 & 17.0 & 1.63 & 1.19 & 1.38 \\
\hline
\end{tabular}


Table 4. Fitted kinetic parameters in the Langmuir Hinshelwood reaction rate of propylene oxidation reaction for various monolith reactors $(100,200,400$, and $600 \mathrm{cpsi})$. The $95 \%$ confidence limits are also provided.

\begin{tabular}{ccccc}
\hline CPSI & $\mathbf{b}_{1}$ & $\mathbf{b}_{2}$ & $\mathbf{b}_{\mathbf{3}}$ & $\mathbf{b}_{\mathbf{4}}$ \\
& $\left(\mathbf{m o l e s} / \mathbf{m}^{3} / \mathbf{s}\right)$ & $(\mathbf{K})$ & $\left(\mathbf{m o l e s} / \mathbf{m}^{3} / \mathbf{s}\right)$ & $(\mathbf{K})$ \\
\hline 100 & $8.01 \times 10^{15} \pm 5.11 \times 10^{17}$ & $1.19 \times 10^{4} \pm 3.55 \times 10^{4}$ & $1.01 \times 10^{3} \pm 3.23 \times 10^{4}$ & $-1.13 \times 10^{2} \pm 6.26 \times 10^{3}$ \\
\hline 200 & $4.40 \times 10^{15} \pm 2.98 \times 10^{15}$ & $1.15 \times 10^{4} \pm 1.15 \times 10^{4}$ & $5.29 \times 10^{2} \pm 5.29 \times 10^{2}$ & $-4.67 \times 10^{2} \pm 2.52 \times 10^{2}$ \\
400 & $8.44 \times 10^{17} \pm 9.32 \times 10^{16}$ & $1.21 \times 10^{4} \pm 3.43 \times 10^{1}$ & $1.04 \times 10^{2} \pm 2.39 \times 10^{1}$ & $-1.01 \times 10^{2} \pm 2.31 \times 10^{1}$ \\
600 & $4.94 \times 10^{15} \pm 1.52 \times 10^{16}$ & $1.21 \times 10^{4} \pm 8.56 \times 10^{3}$ & $1.11 \times 10^{3} \pm 3.40 \times 10^{3}$ & $-1.00 \times 10^{2} \pm 4.42 \times 10^{3}$ \\
\hline
\end{tabular}


Table Error! No text of specified style in document.5. The entire set of 37 experiments conducted in four monoliths and two capillary probes. The asterisk (*) denotes experiments with $0.3 \%$ propylene in the feed; those without had $0.17 \%$ propylene in the feed. 


\begin{tabular}{|c|c|c|c|c|c|c|c|c|}
\hline No. & $\underset{(\operatorname{sccm})}{F_{T}}$ & CPSI & $\begin{array}{c}\text { ID } \\
(\mu \mathbf{m})\end{array}$ & $\begin{array}{c}\text { OD } \\
(\mu \mathbf{m})\end{array}$ & $\begin{array}{c}\Delta \mathbf{Z} \\
(\mathbf{m m})\end{array}$ & $\log (\phi)$ & $\mathbf{Z}^{\prime}$ & $\begin{array}{c}\mathbf{T}_{\mathbf{f}} \\
\left({ }^{0} \mathrm{C}\right)\end{array}$ \\
\hline 1 & 8000 & 100 & 110 & 170 & 16 & 3.63 & 0.13 & 246 \\
\hline 2 & 8000 & 100 & 110 & 170 & 17 & 2.88 & 0.13 & 232 \\
\hline 3 & 9000 & 100 & 110 & 170 & 18 & 3.05 & 0.13 & 231 \\
\hline 4 & 8000 & 100 & 110 & 170 & 11 & 3.45 & 0.33 & 224 \\
\hline $5^{*}$ & 12000 & 100 & 110 & 170 & 0 & 3.09 & 0.96 & 150 \\
\hline $6^{*}$ & 10000 & 100 & 110 & 170 & 0 & 3.31 & 0.93 & 143 \\
\hline 7 & 11000 & 100 & 150 & 363 & 0 & 3.54 & 0.87 & 202 \\
\hline 8 & 8000 & 100 & 150 & 363 & 0 & 3.50 & 0.73 & 196 \\
\hline 9 & 9000 & 100 & 150 & 363 & 6 & 3.06 & 0.53 & 201 \\
\hline 10 & 8000 & 200 & 110 & 170 & 8 & 2.66 & 0.13 & 233 \\
\hline 11 & 11000 & 200 & 110 & 170 & 5 & 2.68 & 0.20 & 210 \\
\hline 12 & 8000 & 200 & 150 & 363 & 7 & 2.72 & 0.13 & 234 \\
\hline 13 & 11000 & 200 & 150 & 363 & 5 & 2.51 & 0.20 & 210 \\
\hline 14 & 8000 & 200 & 150 & 363 & 17 & 2.95 & 0.11 & 248 \\
\hline 15 & 11000 & 200 & 150 & 363 & 6 & 2.70 & 0.16 & 216 \\
\hline $16^{*}$ & 11000 & 200 & 110 & 170 & 0 & 3.01 & 0.68 & 157 \\
\hline $17^{*}$ & 11600 & 200 & 110 & 170 & 0 & 3.10 & 0.88 & 152 \\
\hline $18^{*}$ & 12000 & 200 & 110 & 170 & 0 & 3.31 & 0.96 & 131 \\
\hline $19^{*}$ & 10000 & 200 & 110 & 170 & 0 & 3.09 & 0.92 & 121 \\
\hline 20 & 11000 & 400 & 110 & 170 & 7 & 3.95 & 0.27 & 181 \\
\hline 21 & 11000 & 400 & 150 & 363 & 7 & 3.83 & 0.27 & 182 \\
\hline 22 & 8000 & 400 & 150 & 363 & 13 & 3.22 & 0.11 & 180 \\
\hline 23 & 8000 & 400 & 110 & 170 & 13 & 3.34 & 0.11 & 180 \\
\hline $24^{*}$ & 10000 & 400 & 110 & 170 & 0 & 3.77 & 0.97 & 65 \\
\hline 25 & 9000 & 400 & 110 & 170 & 3 & 2.84 & 0.84 & 82 \\
\hline 26 & 9000 & 400 & 110 & 170 & 6 & 2.91 & 0.56 & 87 \\
\hline 27 & 8000 & 400 & 110 & 170 & 4 & 2.77 & 0.60 & 80 \\
\hline 28 & 8000 & 600 & 110 & 170 & 17 & 2.56 & 0.12 & 238 \\
\hline 29 & 8000 & 600 & 150 & 363 & 15 & 2.18 & 0.13 & 239 \\
\hline 30 & 11000 & 600 & 150 & 363 & 4 & 2.13 & 0.64 & 200 \\
\hline 31 & 8000 & 600 & 150 & 363 & 4 & 1.98 & 0.60 & 204 \\
\hline $32^{*}$ & 10000 & 600 & 110 & 170 & 0 & 2.75 & 0.96 & 159 \\
\hline $33^{*}$ & 10000 & 600 & 110 & 170 & 0 & 2.57 & 0.96 & 154 \\
\hline $34^{*}$ & 10600 & 600 & 110 & 170 & 4 & 2.28 & 0.91 & 157 \\
\hline $35^{*}$ & 12000 & 600 & 110 & 170 & 3 & 2.63 & 0.93 & 170 \\
\hline 36 & 8000 & 600 & 110 & 170 & 3 & 1.89 & 0.20 & 205 \\
\hline 37 & 8000 & 600 & 110 & 170 & 0 & 1.87 & 0.24 & 181 \\
\hline
\end{tabular}


Table 6. Numerical constants and parameters used in the simulations.

\begin{tabular}{|c|l|}
\hline Constant & \multicolumn{1}{|c}{ Value } \\
\hline$\Delta \mathbf{H}$ & $-1925.9 \times 10^{3} \mathrm{~J} / \mathrm{mol}$ \\
\hline $\mathbf{L}$ & $7.5 \mathrm{~cm}$ \\
\hline $\mathbf{S h}_{\mathbf{e}}$ & 4.36 \\
\hline$S h_{i \infty}$ & 2.65 \\
\hline$N u_{\infty}$ & 3.2 \\
\hline $\mathbf{k}_{\mathbf{f}}$ & $0.0343 \mathrm{~W} / \mathrm{m} / \mathrm{K}$ \\
\hline $\boldsymbol{\tau}$ & 3 \\
\hline $\boldsymbol{\varepsilon}$ & 0.41 \\
\hline $\mathbf{r}$ & $5 \times 10^{-7} \mathrm{~cm}$ \\
\hline$\Lambda$ & 0.58 \\
\hline
\end{tabular}




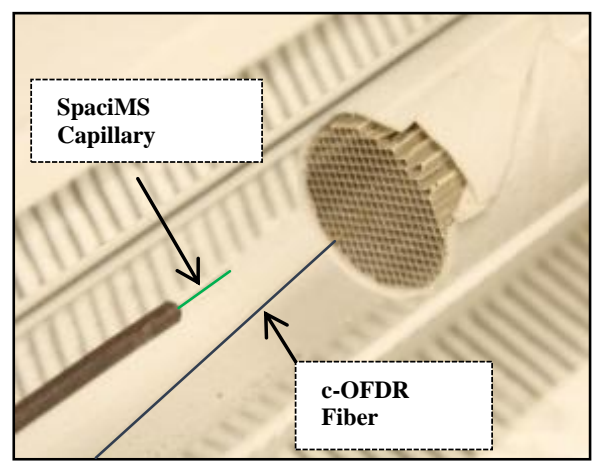

